\title{
VISUAL PERFORMANCE WITH HIGH-CONTRAST CATHODE-RAY TUBES AT HIGH LEVELS \\ OF AMBIENT ILLUMINATION
}

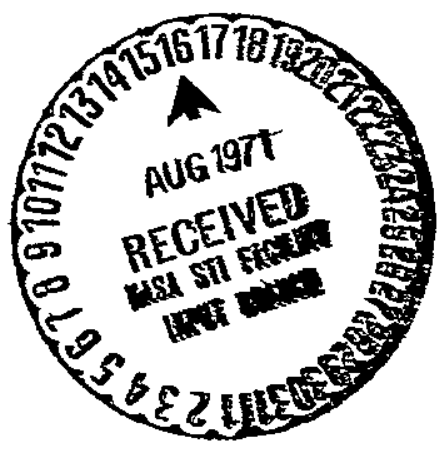

Prepared for:

National Aeronautics and Space Administration Ames Research Center Moffett Field, Calıfornia 94035
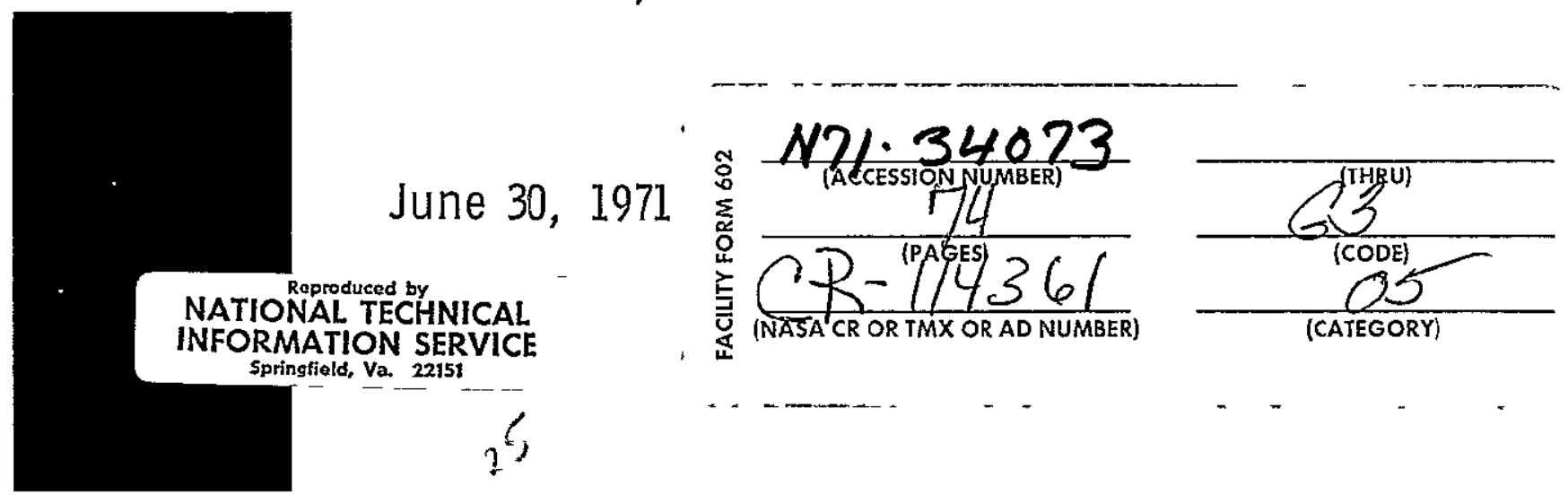
VISUAL PER FORMANCE WITH HIGH-CONTRAST

CATHODE-RAY TUBES AT HIGH LEVELS

OF AMBIENT ILLUMINATION

Contract \# NAS 12-2262

National Aeronautics and Space Admunistration

Ames Research Center

Moffett Field, California 94035

W. B. Knowles

J. W. Wulfeck

Dunlap and Assocrates, Inc.

Western Division

1454 Cloverfield Boulevard

Santa Monjca, Calıfornia 90404

June 30,1971 
This study was carried out under Contract NAS 12-2262 between NASA Ames Research Center and Dunlap and Associates, Inc Wendell D. Chase served as the Project Monitor, and his technical guidance and effectuve administrative support are gratefully acknowledged.

The data reported here were obtained using facilities provided under subcontract by the Display Systems Department of Hughes Aircraft Company. The assistance of Richard N. Winner, Ansis Zilgalvis, and Robert L. Herbelin was especially instrumental in accompisshing this study. Particular thanks are owing to James $F$ Darnold for his generous, patient, expert technical support. 


\begin{abstract}
Gap-detection thresholds and working level preferences were determined for one standard and three experimental high-contract cathode-ray tubes under four levels of ambient illumination, 100 , $1,000,5,000$, and $10,000 \mathrm{ft}-\mathrm{c}$, two angles of incidence, $30^{\circ}$ and $60^{\circ}$, and two angles of regard, $0^{\circ}$ and $-45^{\circ}$ The trace brightnesses required to perform the visual tasks were primarily a function of the reflectances and resulting background brightnesses of the cathode-ray tube faces. The results of this study are related to classical psychophysıcal data on brightness discrimination, earlier work on "masking luminance" for radar displays, and a recent study on visual performance using electroluminescent displays under high ambient illumination.
\end{abstract}


INTRODUCTION $\ldots \ldots \ldots \ldots \ldots \ldots \ldots \ldots \ldots \ldots \ldots \ldots \ldots \ldots \ldots \ldots \ldots$

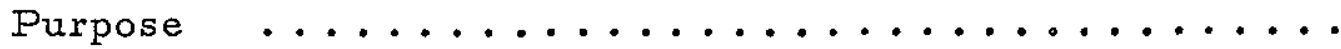

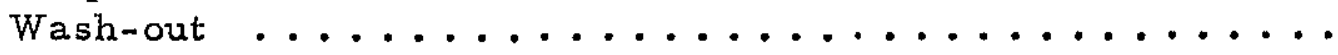

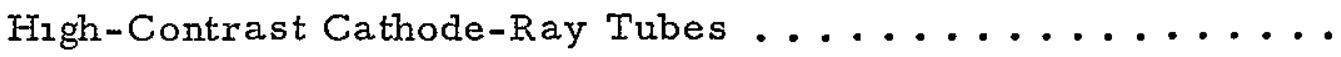

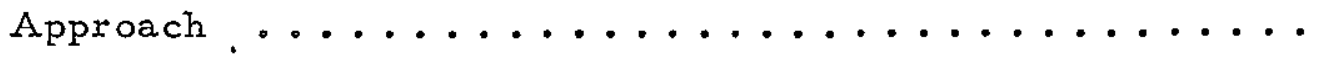

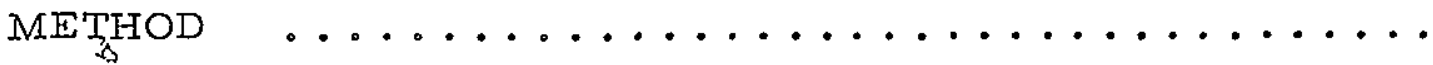

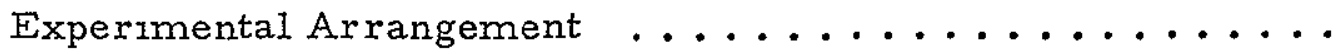

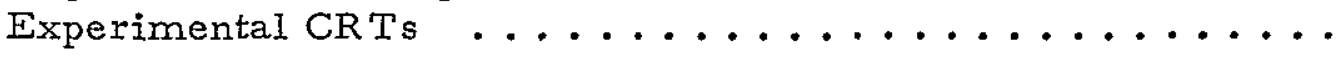

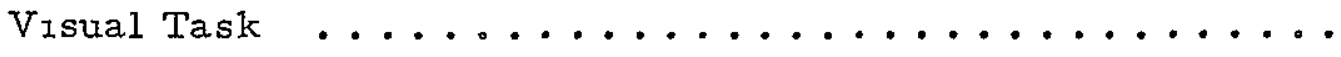

Brightness Measures $\ldots \ldots \ldots \ldots \ldots \ldots$

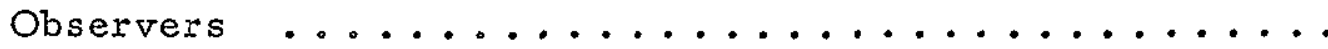

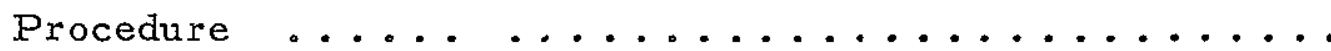

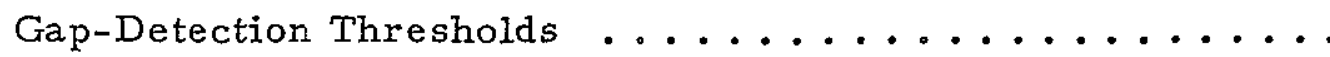

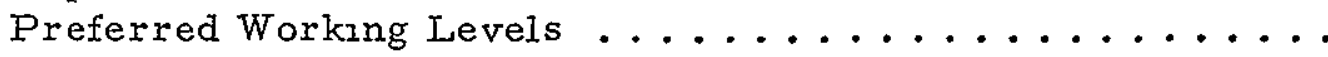

Conversıon From Grid Bias to Brightness Measures .....

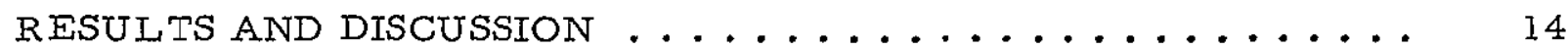

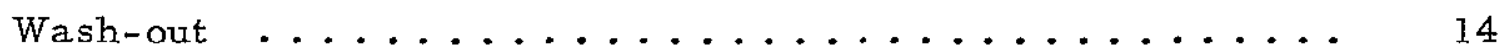

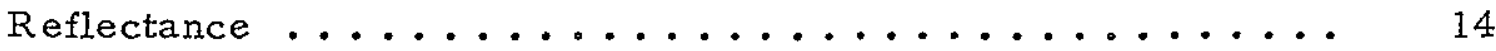

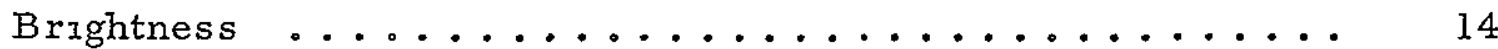

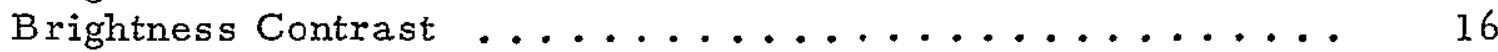

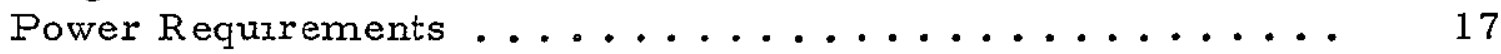

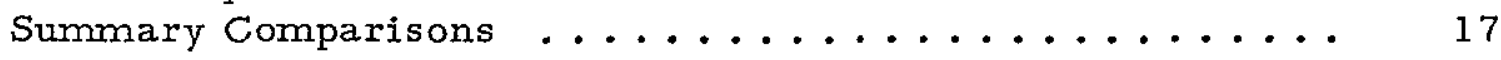

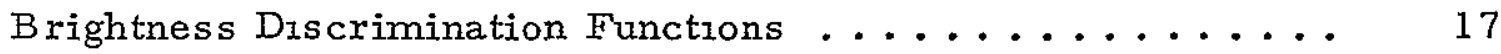

CRT Trace Detection and Display Reading Functions ....... 22

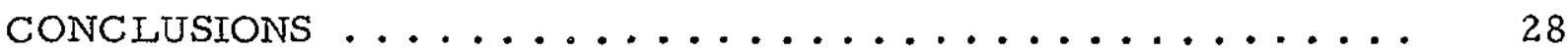

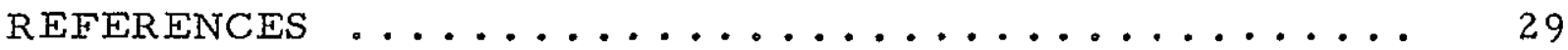


Table of Contents (Continued)

Page

APPENDIX A - SPECIFICATIONS FOR EXPERIMENTAL CRTs ...................... 30

APPENDIX B - COMPUTER DIAGRAMS ......... 38

APPENDIX C ; BRIGHTNESS AND ANODE CURRENT TRANSFER FUNCTION ........... 48

APPENDIX D - DETECTION THRESHOLDS AND WORKING LEVEL PREFERENCES AS A FUNCTION OF AMBIENT ILLUMINATION $\ldots \ldots \ldots \ldots \ldots$ 
Table 1. Summary of Experimental Conditions and Order of Presentation ................

Table 2. Summary Threshold Data for all CRT Displays at Conditions 10,000 ft. -c. Ambient .......... 15

Table 3 Summary Comparison of CRT Displays. 10,000 ft. -c. Ambient, Lamp Position $30^{\circ}$; Observer Position $0^{\circ}$. . .

Table $4 . \quad$ Summary Ranking of CRT Displays ......... 
Figure 2 Experimental arrangement $\ldots \ldots \ldots$

Figure $3 \quad$ Visual display $\ldots \ldots \ldots \ldots \ldots$

Figure 4 Log retinal illuminance of increment ( $\Delta \mathrm{L} S$ in Trolands) as a function of log adapting retinal illuminance for Subject $\mathrm{H}$ in Mueller's 1951

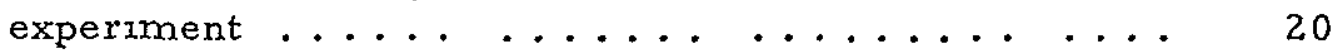

Figure 5 Trace brightness $(\overline{\Delta B})$ vs CRT face brightness (B) for gap-detection thresholds and preferred working levels for CRT displays Westinghouse (W), Electro Vision (E) (partial data), Hartman (H), and Faırchild (F) ... .

Figure 6 Relation between $\Delta I / L$ and $\log L$ as shown by KBnig (open circles) and Brodhun (solid circles) . . . .

Figure 7 Brightness functions for CRT displays Westinghouse (W), Electro Vision (E) (partial data), Hartman ( $\mathrm{H})$, Falrchild $(F) \ldots \ldots \ldots \ldots$

Figure 8 The lowest ambient alluminance required to prevent a radar signal from being detected (1. e., threshold masking luminance), plotted as a function of signal luminance.

Figure 9 Brightness functions for electroluminescent bargraph display .................

Figure 10 Brightness functions for electroluminescent numeric display ...................... 


\section{INTRODUCTION}

\section{Purpose}

The purpose of this study was to compare visual performance using one standard and three expermental high-contrast cathode-ray tubes (CR T) under extremely high levels of ambient illumination such as are encountered during high-altitude flight in direct sunlight. Two questzons of primary interest were

1. Do any of the CRTs "wash-out" under illumination levels

1 approaching maximum operational levels of $10,000 \mathrm{ft}$. $\mathrm{c}$ ?

2. What are the relative merits of the four tubes?

In addition, data were taken at lower levels of ambient illumination of $5,000,1,000$, and 100 ft. $-\mathrm{c}$.

In combination, the data from this study permit a direct comparison of the experimental CRTs in terms of several operational criteria In addition, the data from this study confirm and extend the findings of previous studies on brightness discrimination (Graham, 1965) "masking Illuminance" (Adler, Kuhns, and Brown, 1958) and electroluminescent display legibility (Semple and Goettelmann, 1969), all of which indicate that ambient illumination, i e., Illuminance, is important only insofar as it affects the brightness, 1.e , Iuminance the display face relative to the brightness of the display symbology.

Wash-out

The phosphors of most conventional CRTs are white or very light gray and reflect a very high percentage of the ambient light that falls upon them. For example, the Pl phosphor reflects about 70-80 percent of the incident light.

The visibility of a figure generated on the CR $T$ face depends upon the difference between the amount of light reflected from the face of the tube, $B$, and the amount emitted by the generated figure, $\Delta B$. The proportionate increment in brightness of the trace over the general background, $\Delta B / B$, required to discriminate a figure formed by the trace varies over a wide range depending primarily upon the visual task and the level of the background brightness. 
However, since discrimination depends upon the ratio of the brightnesses, or contrast, it can be seen that if the trace brightness, $\Delta \mathrm{B}$, were set for discrimination against a low level of background brightness, $B$, and then held fixed while the background brightness was increased, the ratio $\triangle B / B$ would be reduced. If contrast is reduced to a low enought value, the trace will not be enought brighter than the background to be discriminated

That is basically what happens when airborne displays "wash-out " Depending upon several factors, including location, time of day, orientation, clouds, haze and altitude, the ambient illumination from the sun can vary over several log units, from less than $100 \mathrm{ft}-c$. under poor visibility conditions at low altitudes to about 10,000 to $15,000 \mathrm{ft} .-\mathrm{c}$ at altitudes of 20,000 to $40,000 \mathrm{ft}$ CR T displays set at brightnesses suitable for relatively low ambient levels may "wash-out" at the highest levels.

High-Contrast Cathode-Ray Tubes

Over practical operating conditions, the maximum brightness of the trace of most CRTs is limited to the order of a few hundred foot-Lamberts. usually the display is operated at levels below a hundred foot-Lamberts Discrimination, then, depends upon finding ways of keeping the luminance of the face of the tube at appropriate low levels.

Hoods, light traps, mesh screens, and filters are devices for preventing ambient light from reaching the reflecting phosphor layer Filters not only reduce the incident light on its way in, they also further reduce the reflected light on its way out, while the emitted light is reduced only on the out-going path. The three experimental CRTs used in this study (Figure 1) represented three different techniques of reducing the background luminance. '

The Electro Vision CRT (VC6AEPl(S) S/N 3) uses a thin-film phosphor. screen A thin-frlm, or transparent phosphor is really a special kind of light trap in which the light goes through the phosphor and is trapped inside the tube.

The Hartman CRT (HC-1101 S/N 2) uses a special'absorptive filter bonded to the face of a standard production CRT. The filter has a narrow region of high transmittance designed to match the spectral output of the CRT to the peak of the spectral sensitivity of the eye Light from other regions of the spectrum is attenuated greatly.

"For detailed technical specifications for the CRTs used in this study, please contact the individual manufacturers. 

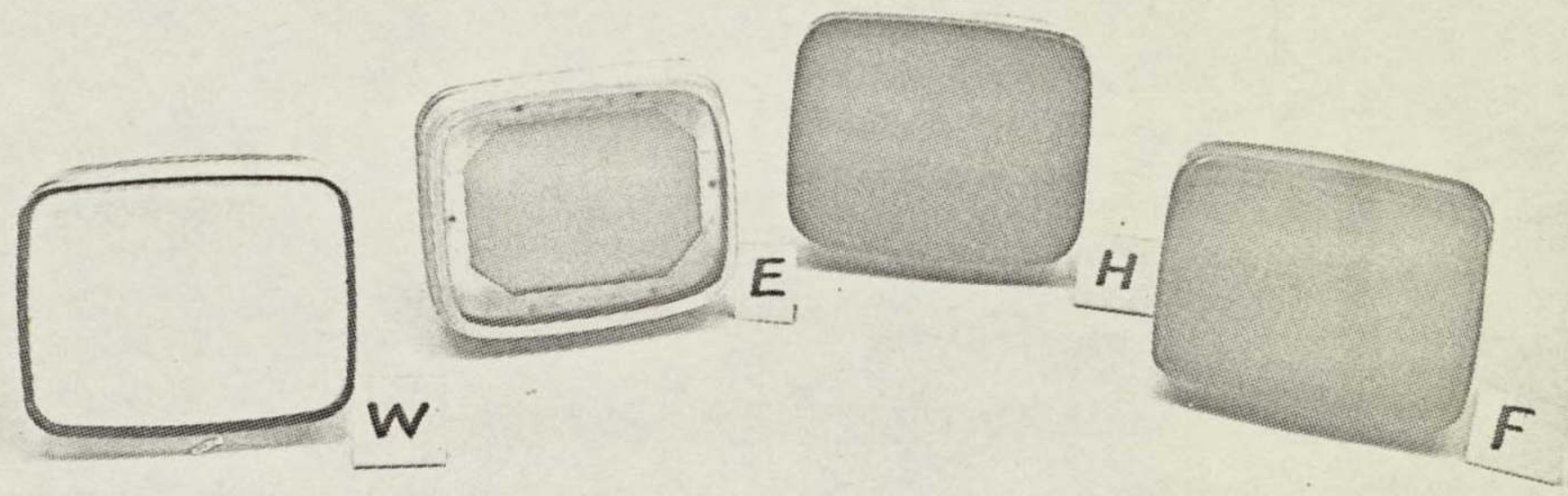

Figure 1. Experimental CRTs. Reflectance values are shown by the gray tone values of the CRT faces. W = Westinghouse (WX-30844P-1), E = Electro Vision (VC6AEPI (S) S/N 3), $\mathrm{H}=$ Hartman $(\mathrm{HC}-1101 \mathrm{~S} / \mathrm{N} 2), \mathrm{F}=$ Fairchild $(\mathrm{KC} 2920 \mathrm{PFC}$ $\mathrm{S} / \mathrm{N} 250658$ ). 
The Fairchild CRT (KC2920PFC S/N 250658) uses a pigmented phosphor. In addition, a nonreflective panel, which also acts like a neutral density filter, was laminated to the front surface.

The Westinghouse CRT (WX-30844P-1) was a standard production CR T . with a conventional P1 phoshor. No attempt had been made to improve the contrast of this CRT. It was used simply to provide a standard conventional CRT against which to compare the experimental CRTs.

\section{Approach}

The general plan of the study was

1. The same operating conditions were used for all four CRTs.

2. A computer-generated direct-write display was used to provide a visual form discrimination task and a tracking task

3. Fixed levels of ambient illumination were provided by high intensity quartzite lamps.

4. Form discrimination thresholds and preferred working levels were determined for four subjects.

5. Data were taken for various combinations of the following conditions

Ambient Illuminance

$$
10,000,5,000,1,000,100 \mathrm{ft.}-\mathrm{c}
$$

Angle of Incidence

$$
30^{\circ}, 60^{\circ}
$$

Angle of Regard

$$
0^{\circ},-45^{\circ}
$$

6 The data were analyzed and the CRTs compared in terms of operational criteria and basic visual parameters 


\section{Experimental Arrangement}

Figure 2 shows the plan view of the expermental arrangement The CRTs were mounted in a plexiglass box on a shelf in a standard equipment rack. The face of the box was painted flat black. The subject sat in a chair with the tracking and detection controls mounted on a right-hand writing arm.

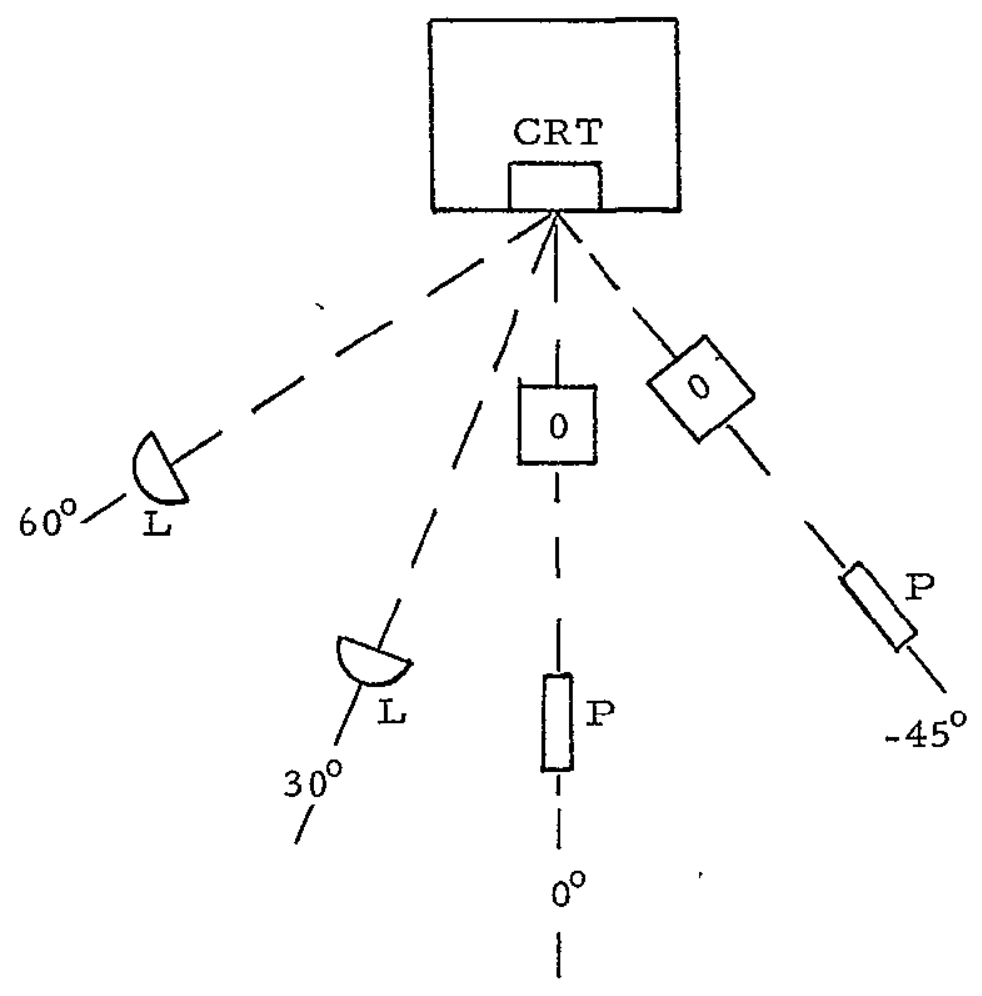

Figure 2. Expermental arrangement. CRT, cathode-ray tube mounted in equipment rack, L, Sun Gun quartzite lamps, $O$, observer seated in chair with tracking and detection controls, P, Pritchard photometer located for background brightness readings. Distances and settings axe described in the text 
The center of the face of the CRT was approximately at eye level (46 in.) In a vertical plane normal to the observer's line of sight when the abserver was seated at the $0^{\circ}$ position. To obtain the $-45^{\circ}$ viewing angle the observer moved his chair to his right, while the CRT and rack remained fixed. The viewing distance was approximately 24 in. from both observer positions.

Ambient illumination was provided by two quartzite lamps (Sun Guns; $3200^{\circ} \mathrm{K}$ ) mounted on a vertical pipe stand at heights of $5 \mathrm{ft}$. and $6 \mathrm{ft}$. The lights were to the left of the observer and were moved along a line either $30^{\circ}$ or $60^{\circ}$ to the normal, i. e, $0^{\circ}$ line, to obtain the desired ambient level and angle of incidence

The basic equation relating ambient illuminance, background luminance, and surface reflectance is

$$
B=R A
$$

$$
\text { where } \begin{aligned}
A & =\text { ambient Illumiance }(\mathrm{ft} .-\mathrm{c} .) \\
B & =\text { background luminance (ft. }-\mathrm{L}) \\
R & =\text { reflectance of the surface }
\end{aligned}
$$

The ambient level was set by placing a sheet of white bond paper with a reflectance of 0.8 over the face of the CRT and adjusting the position of the lights until the photometer reading taken from $30^{\circ}$ off-axis satisifed the equation

$$
P=08 \mathrm{~A}
$$

$$
\text { where. } \quad \begin{aligned}
A & =\text { nominal ambient desired (ft }-\mathrm{c}) \\
\mathrm{P} & =\text { photometer reading to be obtained (ft. }-\mathrm{I.} .) \\
08 & =\text { reflectance of the bond paper }
\end{aligned}
$$

When the Iights had been adjusted, the bond paper was removed and the brightness of the CRT face was measured.

In setting the brightness levels at $60^{\circ}$, the equipment rack was turned so the CRT face was normal to the $60^{\circ}$ line and the photometer readings were taken from the $30^{\circ}$ line. When the lights had been adjusted, the rack was turned back to its standard position and the brightness of the CRT face was measured from the $0^{\circ}$ and $-45^{\circ}$ observer positions 


\section{Expermental CRTs}

The operating characteristics of the four experimental CRTs are summarized in Appendix A All CR Ts were operated at the following voltages

$\begin{array}{lr}\text { Anode Voltage } & 9,000 \mathrm{~V} \\ \text { Grid 1 } & -15 \text { to }-40 \mathrm{~V} \\ \text { Grid 2 } & 300 \mathrm{~V} \\ \text { Grid 4 } & 300 \mathrm{~V}\end{array}$

Trace brightness was varıed by a vernier adjustment on the Grid 1 bias. Grid I voltages were monitored continuously with a digital voltmeter accurate to $\pm .01 \mathrm{~V}$

\section{Visual Task}

The visual task combined two elements, a tracking task and a form discrimination task, to represent the essential features of tasks for which CR Ts are commonly used in aircraft

The display (Figure 3) was generated by an A.D-Four computer (Appendix B). The central tracking display consisted of a short, fixed, horizontal reference line and a longer, movable horizon line A low frequency, white noise generator provided a forcing function to the horizon line The observer attempted to null out the displacement with a pencil grip, spring-loaded, viscously damped, K/s hand-controller Inside-out display-control relations were used

The form discumination task consisted of four rings, one pair above and one pair below the tracking task. A $60^{\circ}$ arc in any one of the four rings could be blanked by the computer to form a gap in the ring The observer indicated the location of the ring containing the gap by pressing a push button in the corresponding position on a panel located on the arm of his chair next to the tracking control

The form discrimination, or gap-detection, task was configured after It was found to be impossible to generate and control a classical Landolt ring visual acuity target accurately enough to be able to consider it any sort of "pure" measure of visual acuity In the operational environment, changes in trace brightness would be accompanied by changes in symbol line-width, symbol-size, and edge-contour gradient A visual acuity test object at low brightness would not be the same object at high brightness. Even if the best possible compensation for changes in target line-width and size were made in the laboratory, differences in contour gradient as a 


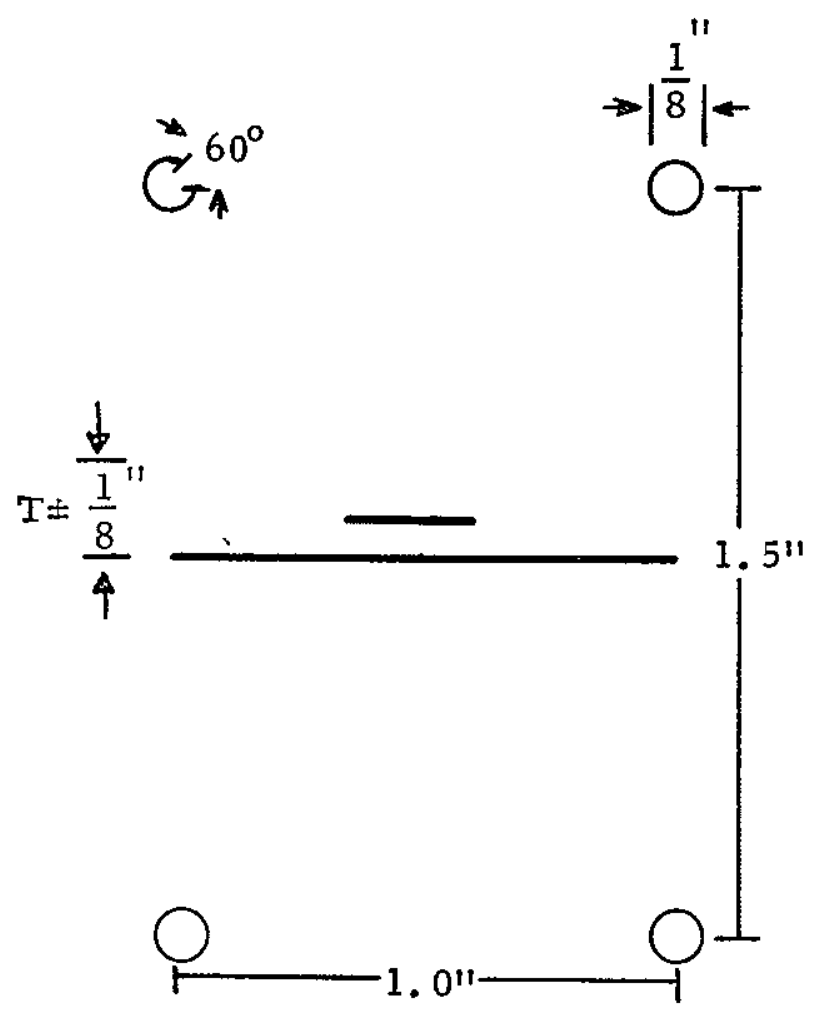

Figure 3. Visual display. The gap-detection task, G, was blanked whenever horizon line of tracking task, T, exceeded the tolerance limits of $\pm 1 / 8$ in from short reference line Postion of the gap was varied randomly by ring and by quadrant.

function of trace brightness would destroy the meaning of "acuity" measures taken wh the target Therefore, the gap-detection task was designed to be visually analogous to the kinds of form discrimination demanded by character recognition in the operational environment and to behave similarly with respect to changes in trace brightness, including "blooming "

The gap-detection task was blanked whenever the tracking error on the central task exceeded a narrow tolerance band Otherwise the detection task was self-paced, 1.e, the display changed whenever the observer pushed a response button The location of the ring with the gap and the position of the gap in the ring were randomly determined from the computer clock The computer also counted the correct and total number of responses 
A trial began when the observer threw a start switch to enable the tracking task and computer logic The trial ended when the operator gave four successive correct detections, or exceeded ten responses

The probability of obtaining four successive correct responses by chance alone is less than 004, so that the thresholds obtained are for virtually 100 percent detectability

No measures of tracking performance were taken since the tracking task was used simply as an auxiliary loading task to force the observer to tume-share between elements of a dynamic task as he would be required to do in most operational tasks The forcing function and tolerance band as well as gap-width were set during a number of preliminary runs to establish a level of task difficulty that the observers reported as moderately demanding

\section{Brightness Measures}

Brightness measures were taken with a Pritchard photometer accurate to \pm 5 percent, full-scale.

Trace brightness was measured using a short focal-length lens and a $6^{\prime}$ aperture The trace brightness vs grid 1 bias function for each tube was determined by taking an average of 12 brightness readings at $100 \mathrm{~V}$ increments over the range of bias settings used by the observers in the experimental trials Three readings were taken around the ring with the gap in it, with the ring positioned in each of the four positions of the figure The line-width of the trace varied with brightness. At the low brightnesses the line just subtended the $6^{\prime}$ field of view, at the high brightness the line-width was two to three times as wide

The anode current vs grid 1 bias function was determined at the same time with an micro-ammeter accurate to $\pm 5 \mu \mathrm{A}$

Average trace brightness, $\overrightarrow{\Delta B}$, and anode current functions for the four CRTs are given in Appendix C.

Background brightness, 1 e , average brightness over the tube face with no figure being generated, was measured using a long focal-length lens and a $2^{\circ}$ aperture. The distance from which the measurements were taken was adjusted so that the area occupied by the tracking and detection figures was subtended within the field of view of the photometer. Background brightness measures were taken along the observer's line of regard each time the ambient lighting condition was changed 


\section{Observers}

Four observers ranging in age from 25-45 were used All reported normal vision with no color anomalies The oldest wore spectacle corrections to $20 / 15$ for astigmatism.

\section{Procedure}

1. An experimental CRT was mounted an the equipment rack.

2. Operatıng voltages were checked and adjusted

3. The spacing of the rings on the display was checked and adjusted

4. The lights were set-up for $10,000 \mathrm{ft}-\mathrm{c}$. ambient at the $30^{\circ}$ incidence angle

5 The brightness of the CRT face without any signal on was read from $0^{\circ}$

6. Gap-detection thresholds in volts were determined for all four observers at $0^{\circ}$

7 The brightness of the CRT face without any signal was read from $-45^{\circ}$

8. Gap-detection thresholds in volts were determined for all four observers at $-45^{\circ}$

9 Preference settings in volts were determined for all four subjects at $0^{\circ}$.

10. The lights were set-up for $10,000 \mathrm{ft}-\mathrm{c}$ ambient at the is $60^{\circ}$ incrdence angle.

11. Steps 5-8 were repeated

12. Another CRT was selected and steps 1-11 were repeated until detection threshold and preference setting data in volts had been obtained for the four CRTs at 10,000 ft -c for a sample of four experimental observers 
The CRTs were tested in the following order Westinghouse, Electro Vision, Hartman, Fairchild. The observers served in the following order $R K, M C, W K, B$. All the data on one CRT were collected on the same day. This design was used to minimize the variance attributable to errors in positioning the lights and to possible variations in the operating conditions of the CRTs.

After the data for the $10,000 \mathrm{ft}-\mathrm{c}$. ambient condition had been obtained, gap-detection and preference data were obtained for three subjects at ambient levels of $5,000,1,000$, and $100 \mathrm{ft} .-\mathrm{c}$. with the lights at $30^{\circ}$ and the observer at $0^{\circ}$.

The data were obtanned as follows

1. An experimental CRT was mounted in the equipment rack

2 Operating voltages were checked and adjusted

3. The spacing of the rings was checked and adjusted

4. The lights were set-up for $5,000 \mathrm{ft}-\mathrm{c}$ ambrent at $30^{\circ}$

5. The brightness of the CRT face without any signal was read from $0^{\circ}$.

6 Gap-detection thresholds in volts were determined for all three observers at $0^{\circ}$

7. Preference settings in volts were determined for all three subjects at $0^{\circ}$

8 The Iights were set-up for $1,000 \mathrm{ft}-\mathrm{c}$

9. Steps 5-7 were repeated.

10. The lights were set-up for $100 \mathrm{ft}-\mathrm{c}$.

11 Stepts 5-7 were repeated

12 Another $C R T$ was selected and steps $1-11$ were repeated until data had been obtained on all tubes

During this second stage of the test, the Electro Vision tube developed a short so that only partial data were obtained at just the 5,000 ft -c level One observer became unavalable so that the brightness functions are based on only three of the original four observers. 
The order in which the experimental conditions were presented is summarized in Table 1

TABIE 1

Summary of Experimental Conditions and Order of Presentation

\begin{tabular}{|c|c|c|c|c|c|c|c|c|c|c|c|}
\hline \multirow{4}{*}{$\begin{array}{l}\text { Ambient Level (ft. - c.) } \\
\text { Light Position (deg ) } \\
\text { Observer Position (deg) } \\
\text { Measure }\end{array}$} & \multicolumn{5}{|c|}{10,000} & \multirow{3}{*}{\multicolumn{2}{|c|}{\begin{tabular}{|c|}
$5,000 * * * *$ \\
30 \\
0
\end{tabular}}} & \multirow{3}{*}{\multicolumn{2}{|c|}{$\frac{1,000 \div \div \div}{30}$}} & \multirow{3}{*}{\multicolumn{2}{|c|}{$\frac{\frac{100 * i t}{30}}{0}$}} \\
\hline & \multicolumn{3}{|c|}{30} & \multicolumn{2}{|c|}{60} & & & & & & \\
\hline & \multicolumn{2}{|c|}{0} & \multirow{2}{*}{\begin{tabular}{|c|}
-45 \\
$\mathrm{DT}$
\end{tabular}} & \multirow{2}{*}{$\frac{0}{\mathrm{DT}}$} & \multirow{2}{*}{$\frac{-45}{D T}$} & & & & & & \\
\hline & $\mathrm{DT} *$ & $W P \because:$ & & & & $\mathrm{DT}$ & WP & $\mathrm{DT}$ & WP & $\mathrm{DT}$ & WP \\
\hline \multicolumn{12}{|l|}{ CRT } \\
\hline Westinghouse & 1 & 3 & 2 & 4 & 5 & 21 & 22 & 23 & 24 & 25 & 26 \\
\hline Electro Vision & 6 & 8 & 7 & 9 & 10 & 27 & 28 & -- & -- & -- & - \\
\hline Hartman & 11 & 13 & 12 & 14 & 15 & 29 & 30 & 31 & 32 & 33 & 34 \\
\hline Fairchild & 16 & 18 & 17 & 19 & 20 & 35 & 36 & 37 & 38 & 39 & 40 \\
\hline \multicolumn{12}{|l|}{ *Gap-Detection Threshold } \\
\hline
\end{tabular}

\section{Gap-Detection Thresholds}

The procedure for determining the gap-detection threshold was fairly simple. After the observer was seated and the high intensity lights were turnedon, the expermenter adjusted the control grid bias until the display was quite visıble The bias was then increased untıl the observer reported that the signal was approaching threshold The experimenter then began a series of detection trials in which the bias was descreased in $010 \mathrm{~V}$. steps between trials until the observer failed to make four successive correct detections within ten responses, or simply gave up. The voltage setting for the last successful trial was recorded as the threshold value for the subject One determination was made for each of the observers and the arithmetic mean of these determinations was taken as the threshold value for the combination of ambient level, incident angle, and viewing angle (See Appendix D, Tables D-1 through $D-8$ ) Only descending series were used because the gap-detection 
threshold was so very near the detection threshold of the entire figure and the detection rings were blanked when the tracking error was out of tolerance. Under these conditions it was not practical to obtain data from ascending series.

Preferred Working Levels

The working preference determinations were made by asking the observer to adjust the bias control until the trace was as bright as he thought he would like to have it if the display were part of an instrument panel The observer was instructed to scan between the CRT display and three or four 4 in meter faces on the equipment rack while performing the detection and tracking task When the observer was satisfied with the setting, the bias voltage was recorded to the neares 001 volt One determination was made for each of the observers and the arithmetic mean of these determinations was taken as the working level preference at each level of ambient illumination (See Appendix D, Tables D-1 through D-8)

\section{Conversion From Grid Bias to Brightness Measures}

The mean detection and mean preference settings in volts, $\bar{V}$, were converted to trace brightness values, $\overline{\Delta B}$, in foot-Lamberts by use of the $\overline{\Delta B}$ vs Gl bias curves (Appendix C) that had been determined previously The $\bar{V}$ and $\overline{\Delta B}$ values for detection and working preference are given in Appendix $D$, Tables D-1 through D-8 for all experimental conditions. 


\section{RESULTS AND DISCUSSION}

Table 2 summarizes the data obtained at the $10,000 \mathrm{ft}-\mathrm{c}$ ambient condition averaged over the four observers at each combination of lamp and observer position for all four CRTs.

Wash-out

It should be noted that under the conditions of this study none of the CRTs washed-out under 10,000 ft -c. and it was possible to obtain enough light output from every CR T to obtain gap-detection thresholds and working level preferences The extreme heat generated by the Sun Gun lamps did not allow the investigation of higher levels of Illumination

\section{Reflectance}

The condition with the lamps at $30^{\circ}$ and the observer at $0^{\circ}$, allows the best estimate of the reflectance of the display surface. In terms of low reflectance values (Table 2) the CRTs ranked.

$\begin{array}{lr}\text { Hartman } & 21 \% \\ \text { Electro Vision } & 83 \% \\ \text { Fairchild } & 240 \% \\ \text { Westinghouse } & 7300 \%\end{array}$

The reflectance values calculated for other combinations of lamp and observer positions are difficult to interpret because of problems in setting the lights at $60^{\circ}$, the gradient of illumination across the face at $60^{\circ}$, and the presence of specular reflections at the $-45^{\circ}$ observer position Note that the values for the Hartman CRT have the greatest variability Front surface reflections and noise were particularly pronounced with this CRT

\section{Brightness}

The brightness of the CRT face, B, is, of course, a direct function of the reflectance of the face. Under $10,000 \mathrm{ft}-\mathrm{c}$ ambient, with the lamps at the $30^{\circ}$ position and the observer at $0^{\circ}$, the following luminance measures (Table 2) were obtained

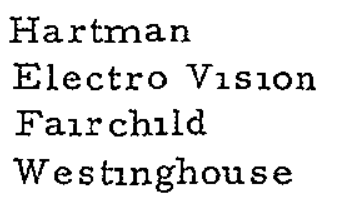

$$
\begin{aligned}
& 210 \mathrm{ft}-\mathrm{L} \\
& 830 \mathrm{ft} \text {. }- \text { L. } \\
& 2450 \mathrm{ft}-\mathrm{L} \text {. } \\
& \text { 7, 300. } 0 \mathrm{ft} .-\mathrm{L}
\end{aligned}
$$




\section{TABLE 2}

Summary Threshold Data for CRT Displays at Conditions: $10,000 \mathrm{ft}-\mathrm{c}$ Ambient

\begin{tabular}{|c|c|c|c|c|c|c|}
\hline \multirow[b]{4}{*}{ Measure } & \multirow[b]{4}{*}{ CRT } & \multicolumn{4}{|c|}{ Light Position } & \multirow{4}{*}{$\begin{array}{l}\text { Working } \\
\text { Preference } \\
\text { With Lights } \\
\text { at } 30^{\circ} \text {, } \\
\text { Observer } \\
\text { at } 0^{\circ}\end{array}$} \\
\hline & & & $30^{\circ}$ & & $60^{\circ}$ & \\
\hline & & \multicolumn{4}{|c|}{ Observer Position } & \\
\hline & & $0^{\circ}$ & $-45^{\circ}$ & $0^{\circ}$ & $-45^{\circ}$ & \\
\hline \multirow{4}{*}{$\begin{array}{l}\text { Reflec- } \\
\text { tance, } \\
R(\%)\end{array}$} & Westinghouse & 73 & 70 & 67 & 61 & - \\
\hline & Electro Vision & .83 & .80 & .55 & .86 & - \\
\hline & Hartman & .21 & .53 & .17 & .31 & $\longrightarrow$ \\
\hline & Falrchuld & 2.4 & 2.4 & 2.1 & 3.0 & - \\
\hline \multirow{4}{*}{$\begin{array}{l}\text { Background } \\
\text { Brightness } \\
\text { B(ft -L.) }\end{array}$} & Westinghouse 7 & 7,300 & 7,500 & 3,000 & 3,500 & - \\
\hline & Electro Vision & 83.0 & 80.0 & 27.5 & 54.0 & - \\
\hline & Hartman & 21.0 & 41.0 & 10.0 & 21.5 & - \\
\hline & Faurchild & 245 & 270 & 98.0 & 190 & - \\
\hline Trace & Westinghouse & 400 & 540 & 110 & 145 & 1250 \\
\hline \multirow{3}{*}{$\begin{array}{l}\text { Brightness } \\
\overline{\Delta B}(\text { ft. }-L)\end{array}$} & Electro Vision & 2.90 & 3.80 & 1.70 & 2.30 & 36.0 \\
\hline & Hartman & 1.20 & 3.00 & 1.20 & 2.10 & 25.0 \\
\hline & Faurchuld & 10.0 & 14.0 & 4.00 & 6.20 & 45.0 \\
\hline \multirow{4}{*}{$\begin{array}{l}\text { Contrast, } \\
\overline{\Delta \mathrm{B}} / \mathrm{B}\end{array}$} & Westinghouse & .055 & .072 & .037 & .041 & .171 \\
\hline & Electro Vision & .035 & .048 & .062 & .038 & .434 \\
\hline & Fartman & .057 & .073 & .120 & .098 & 1.190 \\
\hline & Farrchild & .041 & .052 & .041 & .033 & .184 \\
\hline \multirow{4}{*}{$\begin{array}{l}\text { Anode } \\
\text { Current } \\
\left(\mu \mathrm{A}_{.}\right)\end{array}$} & Westinghouse & 6.0 & 8.5 & 1.5 & 2.0 & 40.0 \\
\hline & Electro Vision & $*$ & $*$ & $*$ & $*$ & 1.0 \\
\hline & Hartman & $*$ & $*$ & * & $*$ & $*$ \\
\hline & Farrchuld & 2.0 & 3.5 & $*$ & 1.0 & 28.0 \\
\hline
\end{tabular}

*Anode Current $<0.5 \mu \mathrm{A}$. 
The corresponding trace brightness, $\overline{\Delta B}$, at detection and at preferred workıng level (Table 2) were

\begin{tabular}{lrrrr} 
& \multicolumn{1}{c}{ Detection } & & Preference & Increase \\
Hartman & $12 \mathrm{ft}-\mathrm{I}$ & & $25 \mathrm{ft}-\mathrm{L}$ & $1980 \%$ \\
Electro Vision & $2.9 \mathrm{ft}-\mathrm{I}$ & $36 \mathrm{ft}-\mathrm{I}$ & $1140 \%$ \\
Farrchild & $100 \mathrm{ft}-\mathrm{I}$ & $45 \mathrm{ft}-\mathrm{L}$ & $350 \%$ \\
Westinghouse & $400.0 \mathrm{ft}-\mathrm{L}$ & $1,250 \mathrm{ft}-\mathrm{L}$. & $220 \%$
\end{tabular}

Brightness Contrast

The ratio of the increment in brightness to the level of background brightness, $\triangle B / B$, is the basic parameter controlling detection and preference levels on the display Note that for the $30^{\circ}$ inght position conditions all of the $\overrightarrow{\triangle B} / B$ values are of the same order of magnitude, but that the values for the $-45^{\circ}$ observer position are consistently about 30 percent higher than for the $60^{\circ}$ observer position In terms of the percentage increase in brightness required for off-axis viewing with the lights at the $30^{\circ}$ position (calculated from Table 2 ), the CR Ts ranked

$\begin{array}{lll}1 & \text { Fairchild } & 268 \% \\ 2 . & \text { Hartman } & 28.0 \% \\ 3 & \text { Westinghouse } & 327 \% \\ 4 & \text { Electro Vision } & 37.1 \%\end{array}$

However, with the lights at the $60^{\circ}$ position there was a decrease in the brightness required at the $-45^{\circ}$ observer position for the three experimental CRTs, while an increase in brightness was found for the conventional CRT. In terms of the decrease in brightness required for off-axis viewing with the lights at the $60^{\circ}$ position (calculated from Table 1), the CRTs ranked

$\begin{array}{llll}\text { 1. Electro Vision } & -38 & 7 \% \\ 2 & \text { Farrchild } & -19 & 5 \% \\ 3 & \text { Hartman } & -18 & 3 \% \\ 4 & \text { Westinghouse } & +10 & 8 \%\end{array}$

As indicated previously some of the inconsistencies present in the data from the extreme conditions of lighting and viewing angles apparently are attributable to differences in the reflecting characteristics of the tubes and to difficulties in setting the lights and measuring the background brightness under those conditions The data obtained in this study indicate that all the CRTs were useable under extreme lighting and viewning angles and that there were difference among the tubes as noted above However, if any finer discriminations among the CRTs under the extreme angles of lighting and viewing conditions are required, then the data reported here should be verified with further observations 
Power Requirements

Trace brightn'ess, $\Delta B$, is a function, primarily of beam current per unit area per unit time. Since a direct-writing display was used with writing speed and refresh rate held constant over all elements for all tubes, trace brightness is then directly related to beam current While beam current per se is difficult to measure, anode current is a reasonable first approximation, and can be used to provide a relative index of the power required to produce the required trace brightness The absolute values of anode current vary as a function of writing speed, refresh rate, operating voltage, etc

In terms of anode current, measured to the nearest $0.5 \mu \mathrm{A} .$, the CRTs ranked as follows

\section{Threshold $\quad$ Preference}

\begin{tabular}{|c|c|c|c|}
\hline I. & Hartman & $<0.5 \mu \mathrm{A}$. & $<0.5 \mu \mathrm{A}$. \\
\hline 2. & Electro Vision & $<0.5 \mu \mathrm{A}$. & 1. $0 \mu \mathrm{A}$. \\
\hline & Fair child & $20 \mu A$. & $28.0 \mu \mathrm{A}$. \\
\hline & Westinghouse & $6.0 \mu \mathrm{A}$ & 40.0 \\
\hline
\end{tabular}

Summary Comparisons

Summary data for the four CRTs on several key measures are given in Table 3 A summary ranking of the tubes is given in Table 4

Brightness Discrimination Functions

Data from psychophysical experiments, e g. , Figure 4, indicate the basic relation between $\Delta B$ and $B$. The wide range of reflectances represented in the present sample of four CRTs coupled with a wide range of ambient illumination levels permitted exploration of the same relation for CR T displays

In Figure 5 the $\overline{\Delta B}$ value obtained wh each $C R T$ at each level of ambient illumination is plotted against the corresponding $B$ value obtained for the same CR $T$ under the same ambient level Two sets of curves are plotted, one for gap-detection threshold, and one for working preference. (See Appendix D, Tables D-5 through D-8) 
TABIE 3

Summary Comparison of CRT Displays: 10,000 ft.-c. Ambient;

Lamp Position $30^{\circ}$, Observer Position $0^{\circ}$

\begin{tabular}{|c|c|c|c|c|}
\hline \multirow{2}{*}{ Mcasure } & \multicolumn{4}{|c|}{ CRT } \\
\hline & $\begin{array}{l}\text { Wcsting- } \\
\text { house }\end{array}$ & $\begin{array}{l}\text { Electro } \\
\text { Vision }\end{array}$ & Fantman & F゙a1relalld \\
\hline Reflectance, R $(\%)$ & 73 & .83 & .21 & 2.45 \\
\hline $\begin{array}{l}\text { Contrast, } \Delta B / B \text {, at } \\
\text { Gap Detection }\end{array}$ & .055 & .035 & .057 & .041 \\
\hline $\begin{array}{l}\text { Anode Current At } \\
\left.\text { Gap Detection ( } \mu \mathrm{A}_{.}\right)\end{array}$ & 6.0 & $*$ & $*$ & 2.0 \\
\hline $\begin{array}{l}\text { Increase in Detection } \overline{\Delta \mathrm{B}} / \mathrm{B} \\
\text { At }-45^{\circ} \text { Viewing Angle (\%) }\end{array}$ & 32.7 & 37.1 & 28.0 & 26.8 \\
\hline $\begin{array}{l}\text { Contrast, } \overline{\Delta B} / B \text {, } \\
\text { At Working Preference }\end{array}$ & .171 & .434 & 1.190 & .184 \\
\hline $\begin{array}{l}\text { Anode Current } \\
\text { At Working Preference ( } \mu \text { A.) }\end{array}$ & 40.0 & 1.0 & $*$ & 28.0 \\
\hline
\end{tabular}

*Anode Current $<0.5 \mu \mathrm{A}$. 
TABLE 4

Summary Ranking of CRT Displays

CR T

\begin{tabular}{|c|c|c|c|c|}
\hline \multirow[b]{2}{*}{ Measure } & \multicolumn{4}{|c|}{$\mathrm{CRT}$} \\
\hline & $\begin{array}{l}\text { Wegling- } \\
\text { house }\end{array}$ & $\begin{array}{l}\text { Eloetro } \\
\text { Vision }\end{array}$ & Elaxtman & Fanchife \\
\hline Reflectance & 4 & 2 & 1 & 3 \\
\hline $\begin{array}{l}\text { Increase in Brightnes: } \\
\text { for Off-Axis Viewing } \\
\text { with Lights at } 30^{\circ}\end{array}$ & 3 & 4 & 2 & 1 \\
\hline $\begin{array}{l}\text { Decrease in Brightnes } \\
\text { for Off-Axis Viewing } \\
\text { with Lights at } 60^{\circ}\end{array}$ & 4 & 1 & 3 & 2 \\
\hline $\begin{array}{l}\text { Anode Current } \\
\text { (Working Level) }\end{array}$ & 4 & 2 & 1 & 3 \\
\hline Sum of Ranks & 15 & 9 & 7 & 9 \\
\hline
\end{tabular}




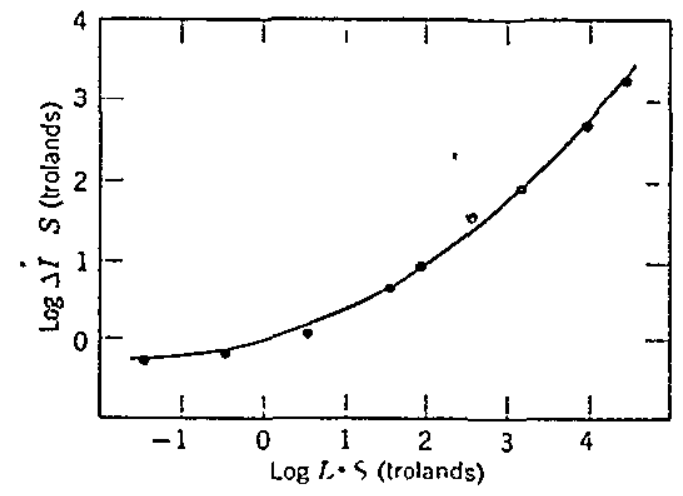

Figure 4 Log retinal illuminance of increment ( $\Delta L S$ in Trolands) as a function of log adapting retinal illuminance for. Subject $H$ in Mueller's 1951 experiment. (As reported in Graham, 1965.)

Figure 5 shows that in general and with minor variations the brightness functions for the various tubes simply spanned different segments of one over-all function The major effects are attributable directly to reducing background brightness regardless of the technique employed The relatively small secondary effects are probably attributable to differences in front surface noxse, color contrast, and other variables

The two sets of curves in Figure 5 also demonstrate that the preferred workıng brightness levels vary as a function of background levels in essentially the same manner as the gap-detection threshold level but that the preference levels are about an order of magnitude greater than the threshold levels In other words, while the general form of the brightness function is similar for different tasks the absolute level required varies as a function of the task

Data from classical psychophysical studies of brightness discrimination are most often expressed in terms of contrast, $\Delta B / B$, vs $B$, e g, Figure 6 The functions obtamed in the present study are replotted in terms of $\log$ $\overline{\Delta \mathrm{B}} / \mathrm{B}$, vs. $\mathrm{B}$ in Figure 7 It can be seen that the contrasts obtained in this study for gap-detection threshold compare quite well with the values reported in Graham (1965), except for the lower range of background brightness The determinations in this region were made with the Fartman CRT, and the observers also reported that the front surface of that CRT was especially norsy 


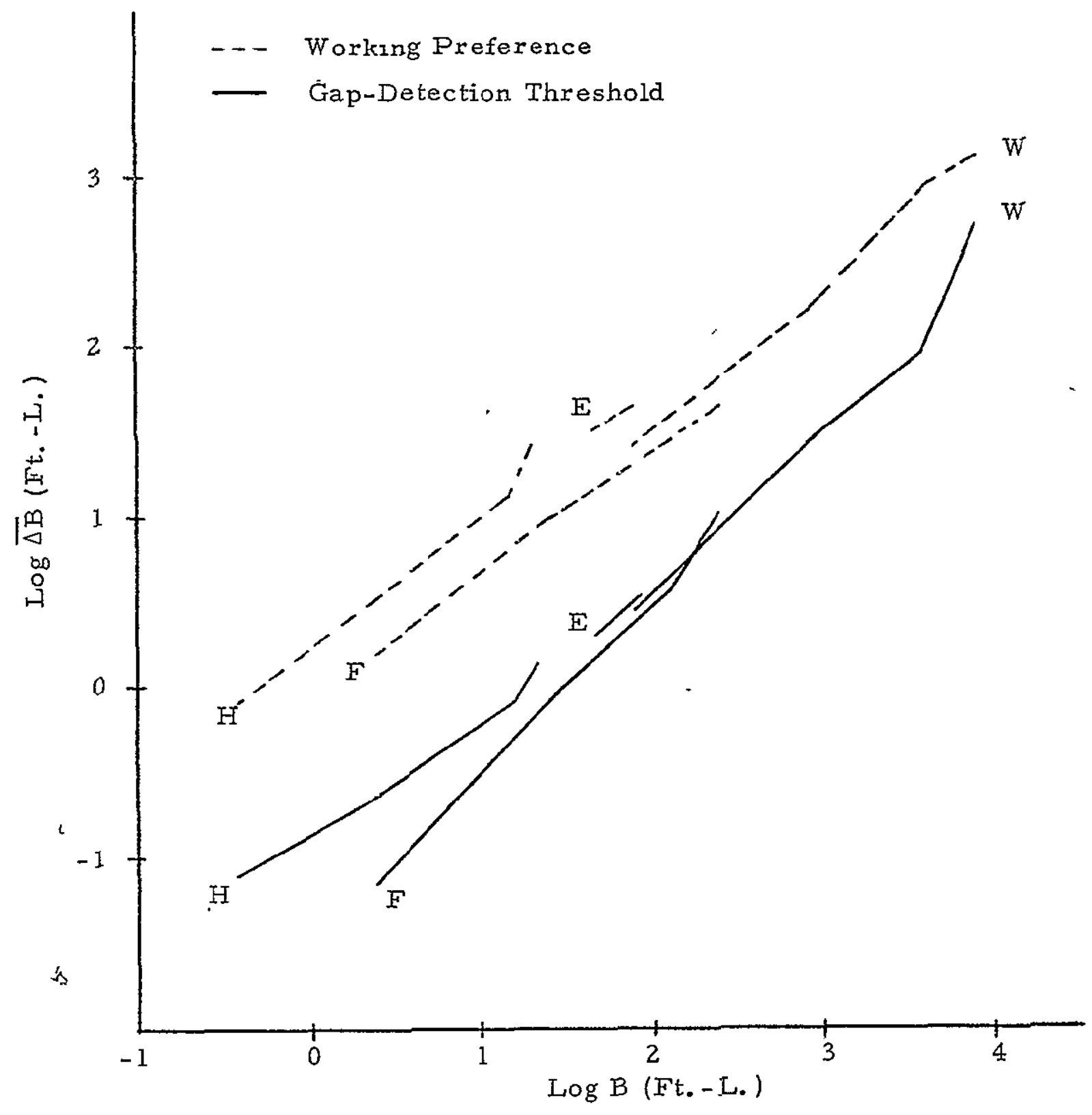

Figure 5. Trace brightness ( $\overline{\Delta B})$ vs CRT face brightness (B) for gap-detection thresholds and preferred working levels for CRT displays. Westinghouse (W), Electro Vision (E) (partial data), Fartman (H), and Farchild (F). (See Appendix D, Tables D-5 through D-8.) 
The differences between gap-detection threshold levels and preferred working levels are also shown in Figure 7.

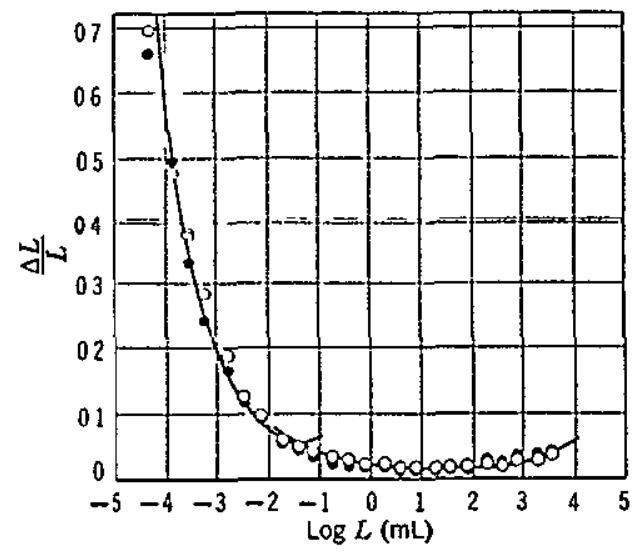

Figure 6. Relation between $\Delta \mathrm{L} / \mathrm{L}$ and $\log \mathrm{L}$ as shown by Kónzg (open circles) and Brodhun (solid circles). (From K'onig and Brodhun 1889 as reported by Graham, 1965.)

CRT Trace Detection and Display Reading Functions

The results obtained in the present study using CRTs are in general agreement with the results of classic psychophysical studies reported as early as 1889 Small differences among the results are attributed to secondary effects, most likely due to differences among stimulus characteristics in the "classical" laboratory and in the "operational" laboratory, such as color temperature of the illuminants effecting color contrast, front surface noise on the CRTs, and the Like.

Operationally analogous data have also been obtained by Adler, Kuhns, and Brown (1953) who measured the threshold masking luminance on a radar scope face produced by ambient illuminations expected to be encountered operationally in aircraft The signal to be masked was a trace $15^{\circ}$ un visual angle Signal luminance was varied from below $-1.0 \log \mathrm{mL}$ to above $1.5 \log \mathrm{mL}$ Masking luminance was found to range from less than $-15 \log \mathrm{mL}$ to more than $3.0 \log \mathrm{mL}$

The study by Adler, et al (1953) was essentially an experiment on CRT wash-out, $I \mathrm{e}$, how much background brightness is required to washout the signal? The results of the Adler study are presented in Figure 8 


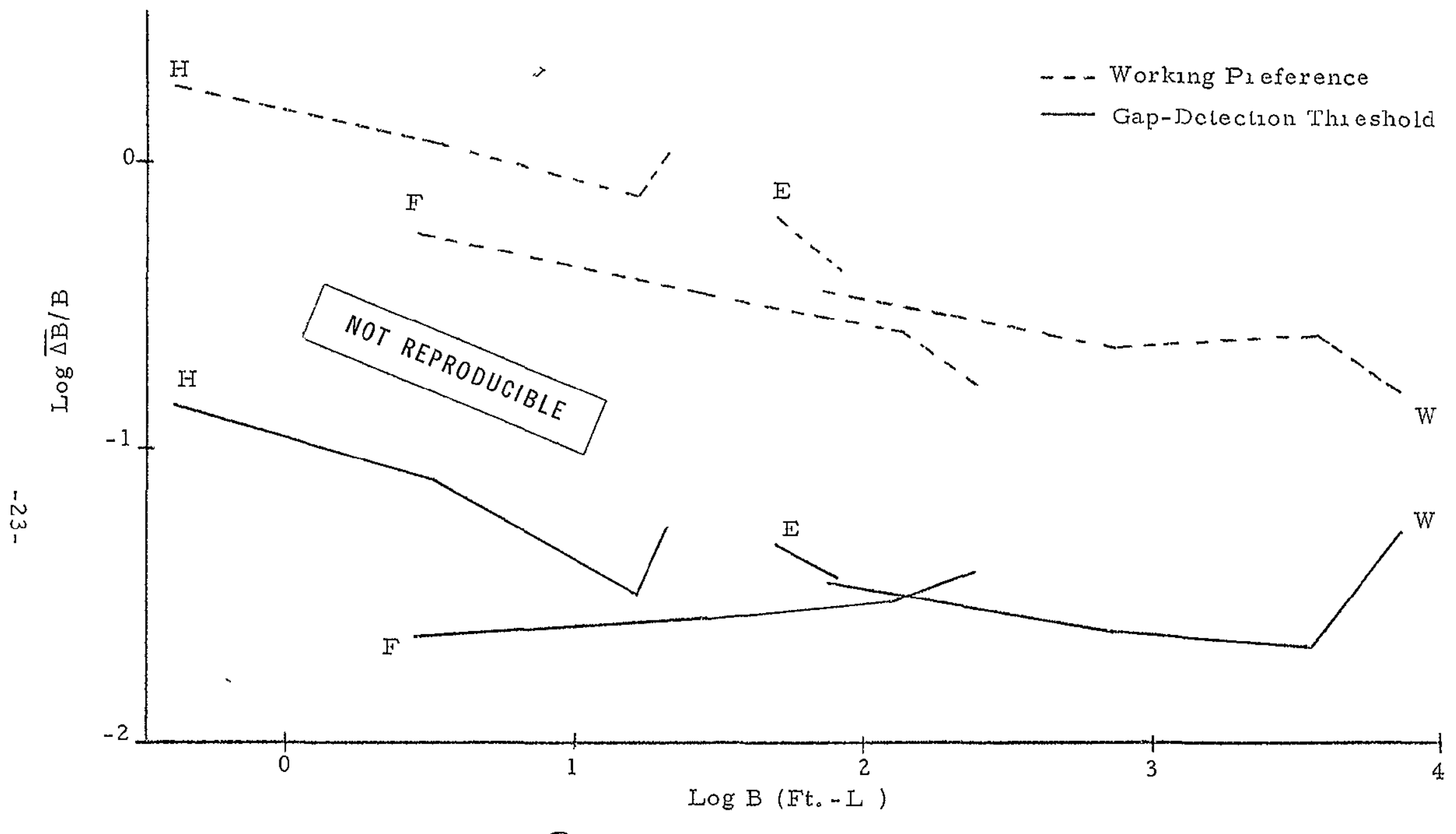

Figure 7. Brightness functions fol CRT displays Westinghouse (W), Electro Vision (E) (partial data), Had lman (H), Falichild (F). (Sce Appendix D, Tables D-5 through D-8) 


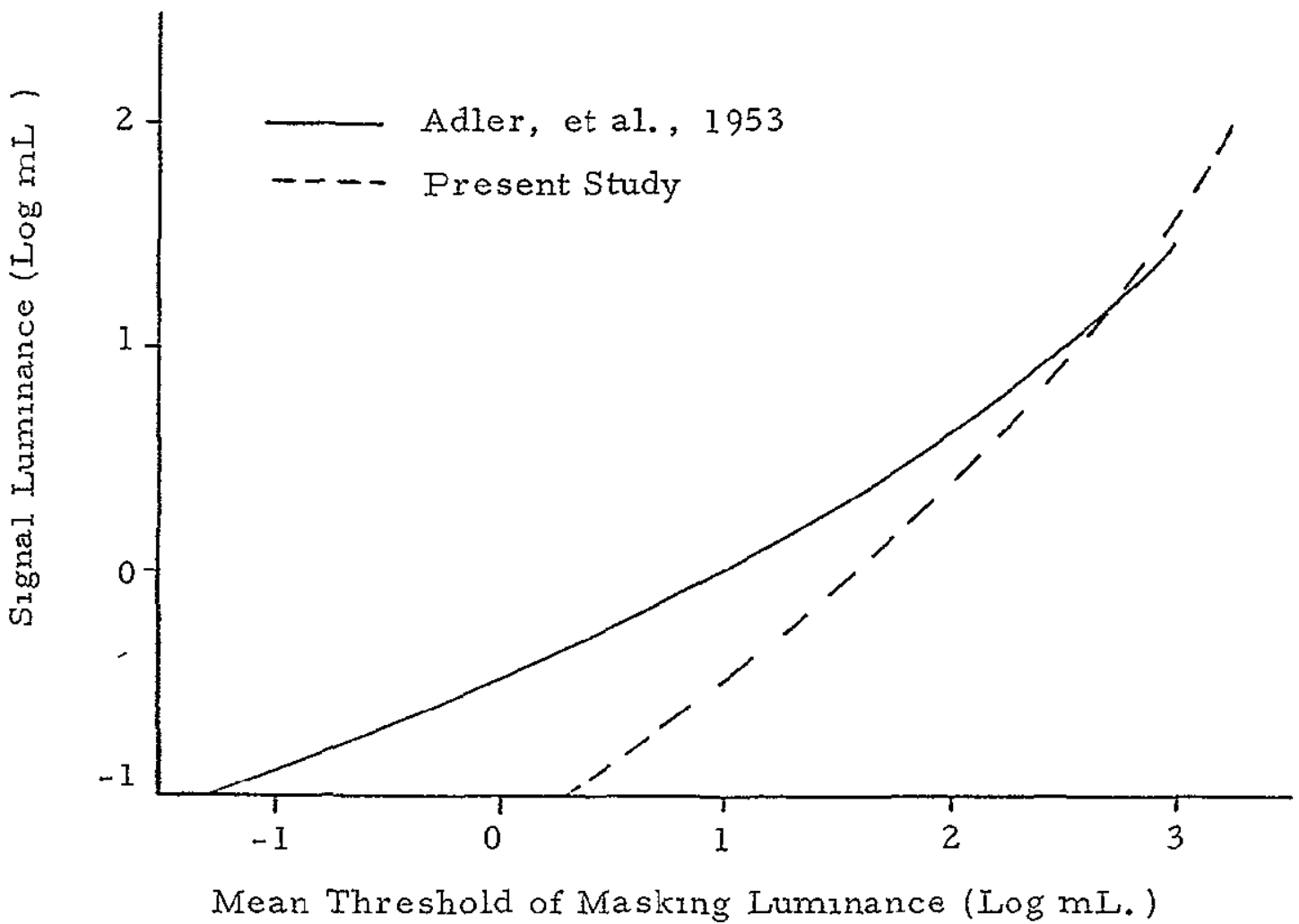

Figure 8. The lowest ambient illuminance required to prevent a radar signal from being detected ( 1 e., threshold masking luminance), plotted as a function of signal luminance. (After Adler, et al., 1953 as reported in Wulfeck, et al, 1958.) Dashed curve is plot of gapdetection data from present experiment. 
For comparison the data from the present study in Figure 5 have been converted to $\log \mathrm{mL}$. and replotted as the dashed curve superimposed on the data by Adler et al. in Figure 8.

In spite of differences in experimental conditions, correspondence of the results seems remarkable, especially at the high end of the masking range, which is the part of most interest. The increasing discrepancies between the two sets of data as low luminances are reached are very likely attributable to averaging data from Figure 5 across the experimental CRTs and to different CRT effects in performing the function for which they were designed.

So far the present results have been demonstrated to agree with classically obtained brightness discrimination data and with operational laboratory CRT display data using a trace masking criterion

Data obtained by Semple and Goettelmann (1969) under similar ranges of ambient illumination, but with somewhat different visual tasks using electroluminescent displays, permit comparison of the brightness functions for CRT displays with the brightness functions for electroluminescent displays

Results from the study by Semple and Goettelmann (1969) are plotted in Figures 9 and 10. The data in Figure 9 were taken using an electroluminescent bar-graph display under ambient levels of 500, 5,000 and 10,000 ft. -c.

The data in Figure 10 were taken using a numeric display under the same levels of ambient illumination

Shree performance measures are shown detection threshold, the point at which the observer reported he could just see that the display was on, legibility threshold, the point at whych the observer could read the values portrayed with 100 percent accuracy, comfort setting, the preferred brightness setting averaged over all observers

It is interesting to note that the "detection" and "comfort" functions of the bar-graph display conncide with the "gap-detection threshold" and "working preference" functions of the present study. The corresponding values for the numeric display are about half a log unt higher. Given the differences in visual tasks, this is a rather satisfying agreement. 


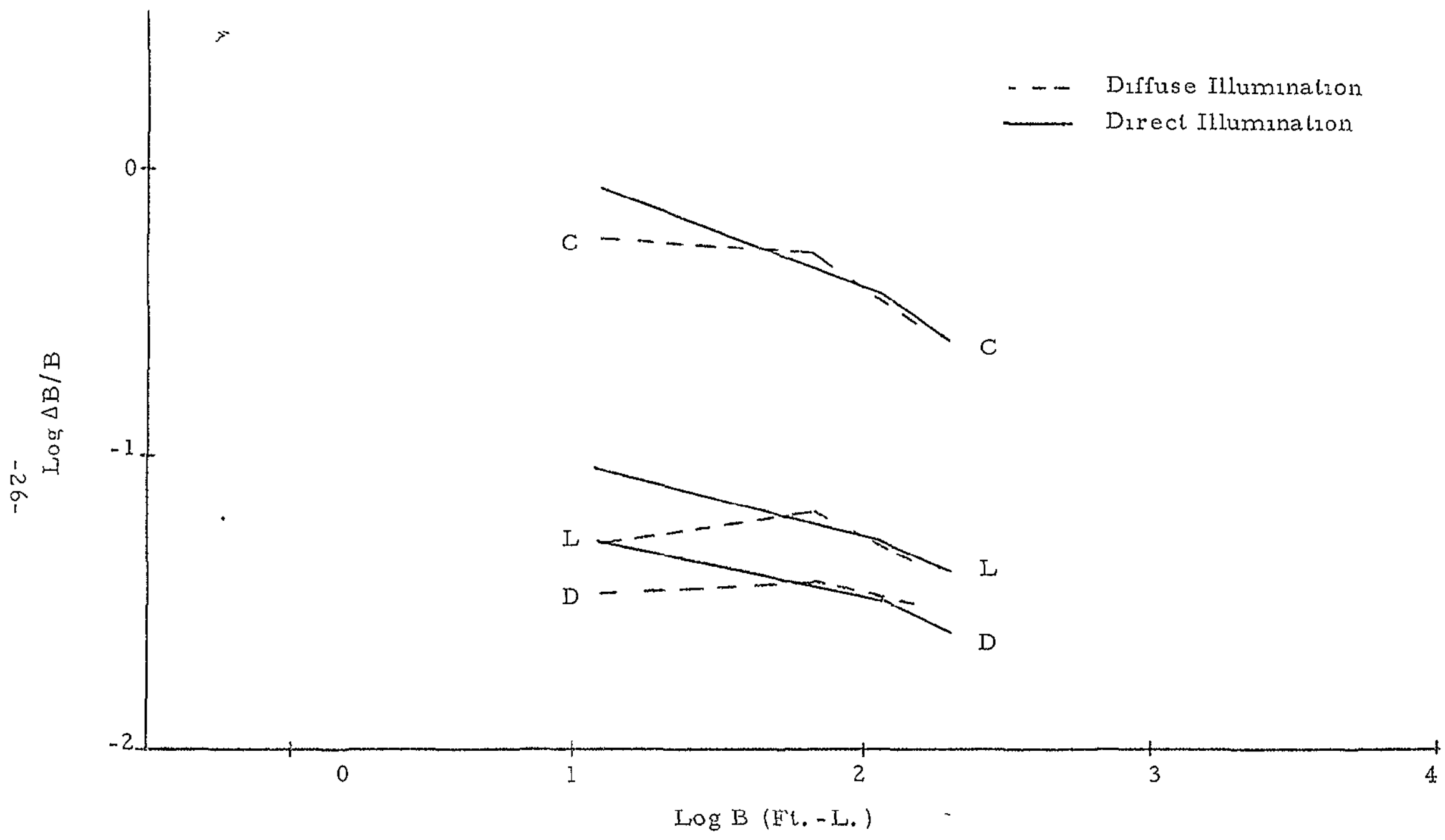

Figure 9. Brighiness functions for clectioluminescent bar-giaph display Deleciron (D), 100 pacent Legrbility (IL) and Comfort (C) thresholds. ( $\Lambda$ dapled fiom Semple and Goettelmann, 1969) 


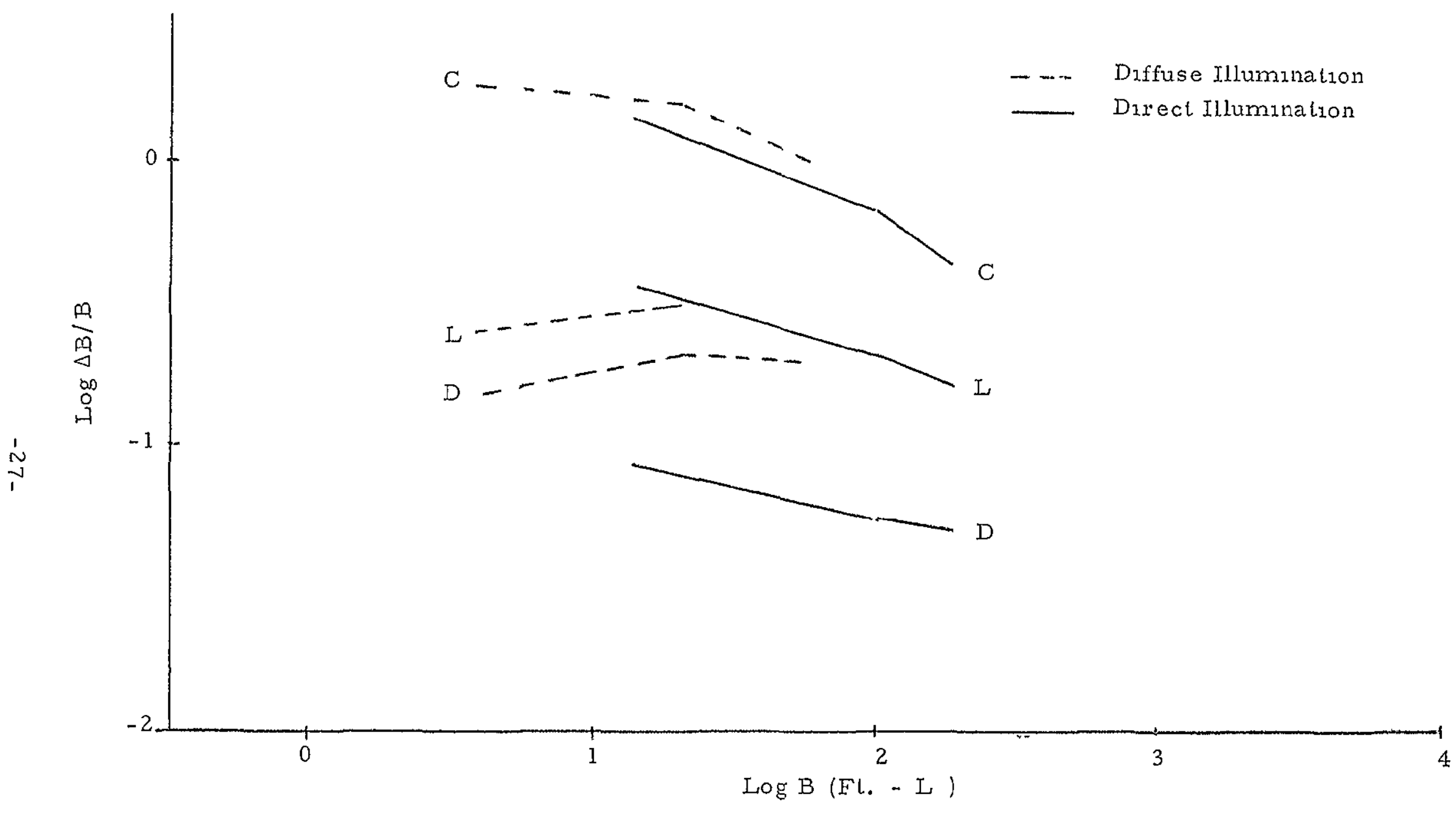

Figure 10 Brightness funchons for electroluminescent numeic display. Delectron (D), 100 pexcent Legibility (L) and Comforl (C) thresholds (Adapled from Scmple and Goclledmann, 1969) 
CONCLUSIONS

1 Under the conditions of this study none of the CRTs tested "washedout" under the highest level of ambient illumination, 10,000 ft $-c$ That is, gap-detection thresholds, and working preference settings were obtained

2. In general, visual performance was primarily a function of background brightness For a given level of ambient illumination, background brightness is determined by the reflectance of the CRT face. Therefore, as a first approximation the tubes may be rank-ordered in terms of their reflectance values

$$
\underline{\text { CRT }} \quad \underline{\text { Reflectance }}
$$

$\begin{array}{lr}\text { Hartman } & 21 \% \\ \text { Electro Vision } & 83 \% \\ \text { Fairchild } & 240 \% \\ \text { Westinghouse } & 73.00 \%\end{array}$

3 Given the reduction of background brightness to an acceptable level, further discrimination among CRTs depends upon secondary factors such as off-axis viewning, color contrast, front-surface noise, power consumption, cost, and trade-offs among them

4 The agreements among the findings of this study, the data from Adler, et al (1953), the data from the Semple and Goettlemann (1969) study and classical psychophysical data (Graham, 1965) indicate that the classical data on brightness discrimination are adequate for firstorder design approximations

5 However, the discrimination functions form a family of curves ranging over one or two log units of brightness depending upon the specific visual task If more precise design data than those reported here are required, a falrly high fidelity simulation of the operational task is in order 


\section{REFERENCES}

Adler, H.E., Kuhns, M.P., and Brown, J.L. Masking of CRT Displays by Ambient Illumination (WADC Technical Report 53-266) Wright Air Development Center, Wright-Patterson Alr Force Base, Ohıo. November 1953 (As reported in Wulfeck, et al. 1958.)

Graham, C. H (ed ) Visıon and Visual Perception. New York John Wiley \& Sons, Inc, 1965.

König, A. and Brodhun, $\mathrm{E}$ Experimentelle Untersuchungen ueber die psychophysische Fundamentalformel in Bezug auf den Gesichtssinn. Sitzungsber. Preuss Akad Wiss., Berlin, 1889, 27, 641-644 (As reported in Graham, 1965.)

Semple, C.A., Jr. and Goettelmann, G. Electroluminescent Display Legibility Contrast Ratio R equirements as a Function of Ambient Illumination (Technical Report MSS-TR-69-01). Northridge, California Manned Systems Sciences, October 1969.

Wulfeck, $J_{0} W$, Weisz, A, and Rabin, Margaret W. Vision in Military Aviation (WADC Technical Report 58-399). Wright Air Development Center, Wright-Patterson Air Force Base, Ohı, November 1958 
APPENDIX A

SPECIFICATIONS FOR EXPERIMENTAL CRTS 


\section{WESTINGHOUSE}

\section{Industrial \& Military CRT}

November 1968

Type WX-30844P-1

Low Voltage Focus, Magnetic Deflection

Compact Monitor Tube

Line $\mathrm{W}_{\text {Idth }}=0.008^{\prime \prime}$

Basic Charactertistics 4-1/2"x 5-1/2" Rectangular

Low Voltage Focus

$90^{\circ}$ Magnetic Deflection

Aluminized

Typical Applications Computer Readout

Monitor

Special Features

Compact

$0008^{\prime \prime}$ Line Width

Electrical

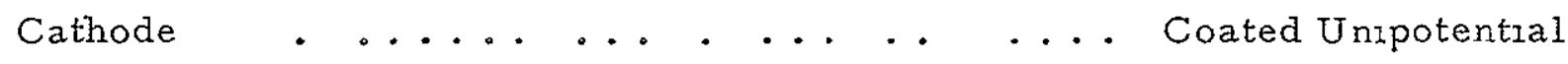

Heatex

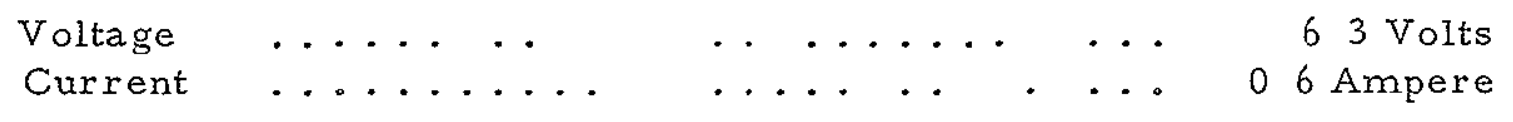

Direct Interelectrode Capacitances

Grid 1 to All Other Electrodes ............. $9 \mathrm{pF}$

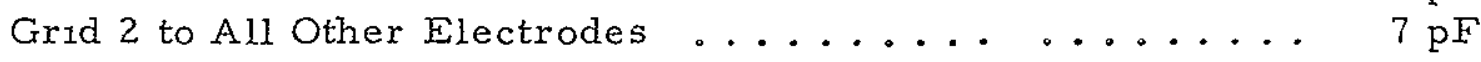

Cathode to All Other Electroles ................. $7 \mathrm{pF}$

Focusing Method . . . . .......... Electrostatic

Deflection $\quad \ldots \quad \ldots \quad \ldots \quad \ldots . . .690^{\circ}$ Magnetic 
Optical

Screen Phosphor $\ldots \ldots \ldots \ldots \ldots$ Note 1

Faceplate

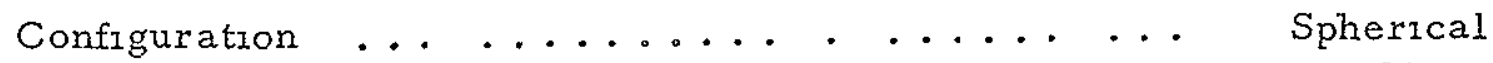

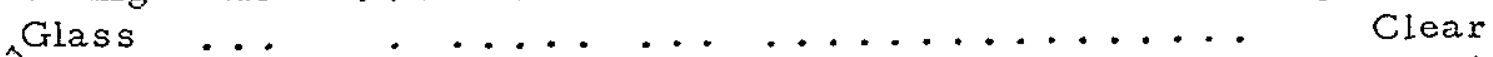

Transmission $\ldots \ldots \ldots \ldots . \ldots \ldots$

Mechanical

Mounting Position .................. Any

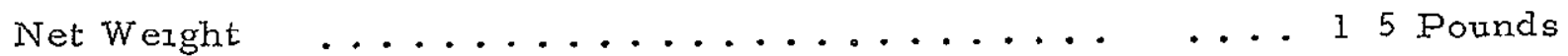

Absolute Maximum Ratings

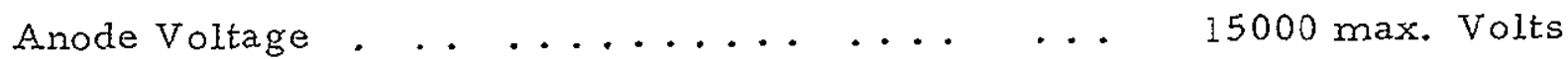

Grid 4 (Focus) Voltage ............ 800 max Volts

Grid 2 Voltage ................ 600 max. Volts

Grid I Voltage

Negative Bras Value ............. $180 \mathrm{max}$ Volts

Positive Bras Value ............ ... 0 max Volts

Posıtıve Peak Value .............. 0 max Volts

Peak Feater-Cathode Voltage

Heater Negative with respect to Cathode

During Warm-up Period of $15 \mathrm{sec}$ max. . 410 max Volts

After Equipment Warm-up Period . .. 180 max Volts

Heater Positive wath respect to Cathode

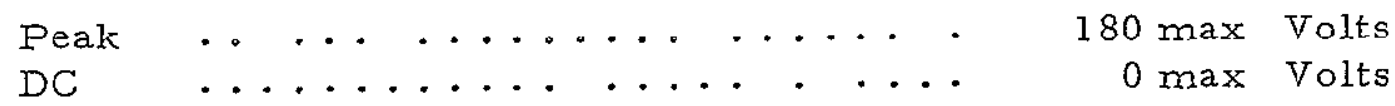

Limitung Circuit Values

Grid I Circuit Resistance ............... 15 max Megohms

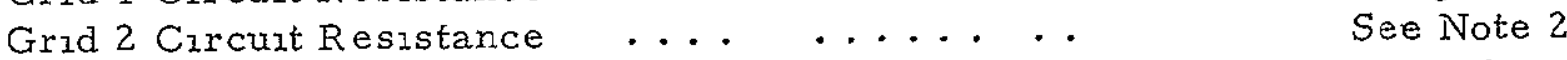

Focus Electrode Circuit Resistance . . . . $10000 \mathrm{~min}$ Ohms 
Typical Operating Conditzons

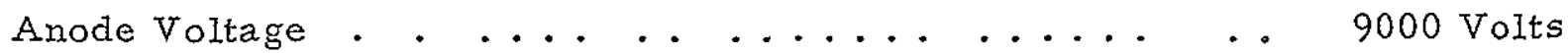

Grid 4 (Focus) Voltage .............. 0 to 300 Volts

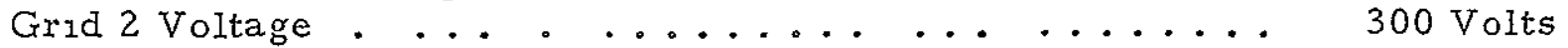

Grid I Spot Cut-off Voltage ..................................... to -30 Volts

Maximum Line W1dth "A" with P4 (note 3) ......... 0. 008 Inch

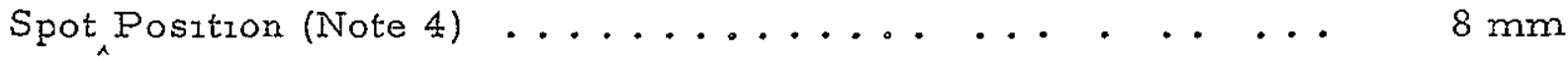

\section{NOTES}

1. Westinghouse Military and Industrial Cathode Ray Tubes can be supplied with most of the standard JEDEC phosphors.

2. A grid 2 circuit resistance of approximately 0.5 megohm should be provided.

3. Line width is measured by the shrinking raster method with a peak current of 100 microamperes. Line widh with other phosphors may vary slightly.

4. With the tube shielded against external magnetic fields, the undeflected focused spot lies within a circle of $8 \mathrm{~mm}$ radius concentric with the faceplate.

5 The WX-number identifies a specific laboratory design, the design and, consequently, the data and type number are subject to change No obligations are assumed to manufacture this particular device in the future unless otherwise arranged. These drawings and specifications are the property of Westinghouse Electric Corporation, Electronic Tube Division, and shall not be reproduced or copied or used as the basis for the manufacture or sale of apparatus and/or devices without permission. 


\section{ELECTRO VISION INDUSTRIES}

DATA SHEET

31 March 1970

TUBE TYPE VC6AEPI (S) (NASA)

S/N'S $1,2 \& 3 \quad$ P.O. TCG 0007

TEST CONDITIONS

$\mathrm{EA}_{2}^{2}-9 \mathrm{KV}, \quad \mathrm{EG}_{2}-300 \mathrm{~V}, \quad \mathrm{EF}-63 \mathrm{~V}, .6 \mathrm{~A}$, Raster $-3 " \mathrm{X} 4^{\prime \prime}$

OPERATIONS $\quad E_{1} \quad I_{2} \quad$ L. $O \quad E A_{1}$ Line $W_{1} d t h \quad I_{k} \max$ OAI

$S / N 1 \quad-39$

$\begin{array}{rrrrl}-18 & 100 & 11 & 50 & .004^{\prime \prime} \\ -9 & 300 & 24 & 0 & .0045^{\prime \prime}\end{array}$

$138^{\prime \prime}$

$S / N 2$

$\begin{array}{rrrrl}-34 & & & & \\ -17 & 100 & 9 & 100 & .004^{\prime \prime} \\ -6 & 300 & 23 & 50 & .0045^{\prime \prime}\end{array}$

1.1 $\quad 8^{\prime \prime}$

$S / N 3$

$\begin{array}{rrrrr}-42 & & & & \\ -20 & 100 & 9 & 150 & .0035^{\prime \prime} \\ -10 & 300 & 31 & 100 & 004^{\prime \prime}\end{array}$

$1.3 \quad 8.25^{11}$ 
HAR TMAN SYSTEMS COMPANY

HIGH CONTRAST TYPE CRT

$\mathrm{HC}-1 \mathrm{I} 01$

$\mathrm{S} / \mathrm{N}-2$

Basic Characteristics

4-1/2" $\times 5-1 / 2 "$ Rectangular

Low Voltage Focus

$90^{\circ}$ Magnetic Deflection

Aluminzzed

Electrical Characteristics

Cathode $\ldots \ldots \ldots \ldots$......................... Unipotentral

Heater

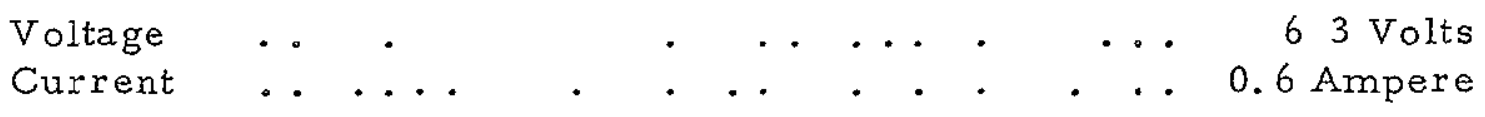

Direct Interrelectrode Capacitances

Grid I to All Other Electrodes .... . . . . . . $9 \mathrm{pF}$

Grad 2 to All Other Electrodes ............ . $7 \mathrm{pF}$

Cathode to All Other Electrodes .......... $7 \mathrm{pF}$

Focusing Method $\ldots \ldots \ldots \ldots \ldots$........ Electrostatic

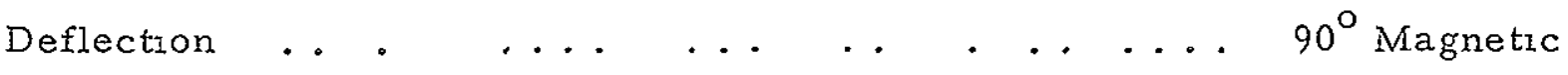

Optical Characteristics

Screen Phosphor $\ldots \ldots \quad \ldots \quad \ldots \quad \ldots \quad \ldots$ P31 Type

Tube Type . . . . . . . . ... . . W W

(Westinghouse)

Mechanical Characteristics

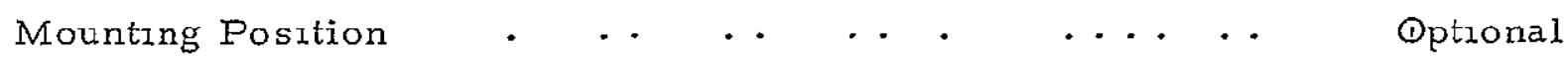

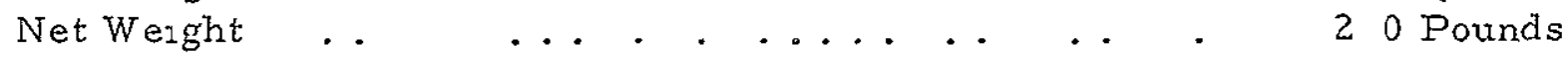


Absolute Maximum Ratings

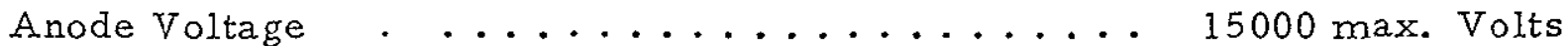
Grid 4 (Focus) Voltage ............. 800 max. Volts Grid 2 Voltage ...... ......... 600 max. Volts Grid 1 Voltage

Negatıve Bias Value ............. 180 max. Volts Positive Bras Value .............. . . 0 max. Volts Posıtive Peak Value .............. 0 max Volts

Peak Heater-Cathode Voltage

Heater Negative with respect to Cathode

During Warm-up Period of $15 \mathrm{sec}$ max. .. 410 max. Volts After Equipment Warm-up Perıod ..... 180 max. Volts

Heater Positive with respect to Cathode

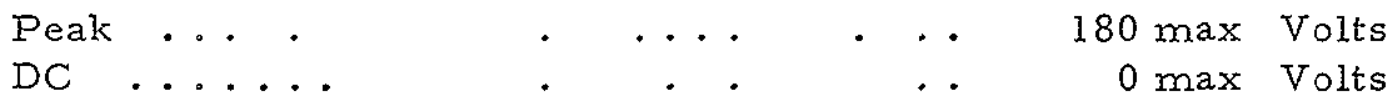

Limitung Circuit Values

Grid 1 Circuit Resistance .... ... . ... I 5 max. Megohms Grid 2 Circuit Resistance ................ See Note 1 Focus Electrode Circuit Resistance . ....... $10000 \mathrm{~min}$. Ohms

Typical Operating Conditions

Anode Voltage .... . . . . . . . . 9 9000 Volts Grid 4 (Focus) Voltage .... ... . 0 to 300 Volts Grid 2 Voltage . . . . . .... 300 Volts Grid 1 Spot Cut-off Voltage .... ... ... -10 to -30 Volts Maximum Line Width (Note 2) ........... . . 0008 inch

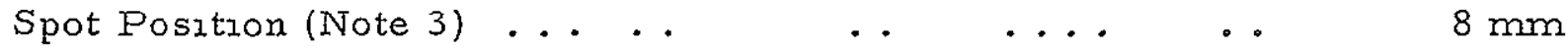
NOTES

1. A grid 2 circuit resistance of approximately 0.5 megohm should be provided

2 Line width is measured by the shrinking raster method with a peak current of 100 microamperes

3. With the tube shielded against external magnetic fields, the undeflected focused spot lines within a circle of $8 \mathrm{~mm}$ radius concentric with the faceplate 


\section{FAIR CHILD}

Cathode-Ray Tube

Type KC2920PFC

Serıal No. 250658

Typical conditions

$$
\begin{aligned}
& 16 \mathrm{KV}=\text { anode } \\
& 500 \mathrm{~V}=\mathrm{G} 2 \\
& 6.3 \mathrm{~V}=\mathrm{EF} \\
& 0-300 \mathrm{~V}=\mathrm{G} 4
\end{aligned}
$$

Mechanical HEA anti-reflection panel laminated onto face of CRT

$$
\text { Overall length } 7-1 / 4 \text { inches }
$$

Basing 8HR

Base B7-208

Base schematic -

Element

Heater

$\mathrm{Gl}$

G2

G4

Cathode

NC

Anode
Pin No

1 and 8

2 and 6

3

4

7

5

Bulb J1-22

Data

Focus $=200 \mathrm{~V}$

Cut-off $G l=-31 \mathrm{~V}$

Zero bias current $=420 \mu \mathrm{A}$

Line brightness $=115 \mathrm{Ft} . \mathrm{L}$ (Note 1)

Reflectivity $=25 \%$

Modulation at $200 \mu \mathrm{A}=23 \mathrm{~V}$

Gas ratio $=10 \mu \mathrm{A}$

Line width at $100 \mu \mathrm{A}=.0075$ inch

NOTE 1 Line brightness taken with $2^{\prime}$ aperture Pritchard Spectrometer at writing speed 6000 inches/second.

NOTE 2 Line brightness and contrast transfer ratio will be improved by increasing anode voltage. Tube can be operated at $18 \mathrm{KV}$ with an increase of Ine brightness of $30 \%$ 
APPENDIX B

COMPUTER DIAGRAMS

$-38-$ 


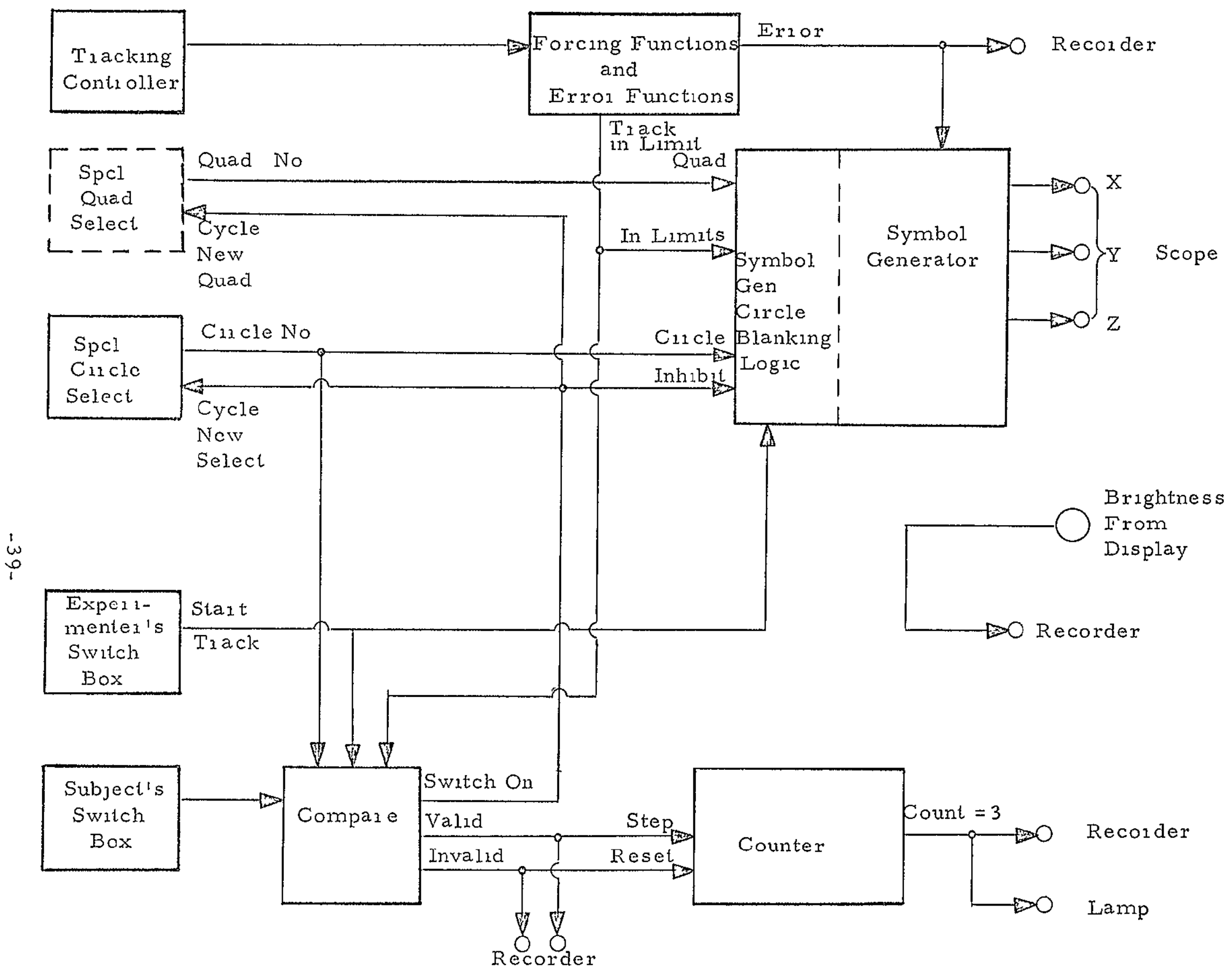

Figure $B-1$. System block diagram 


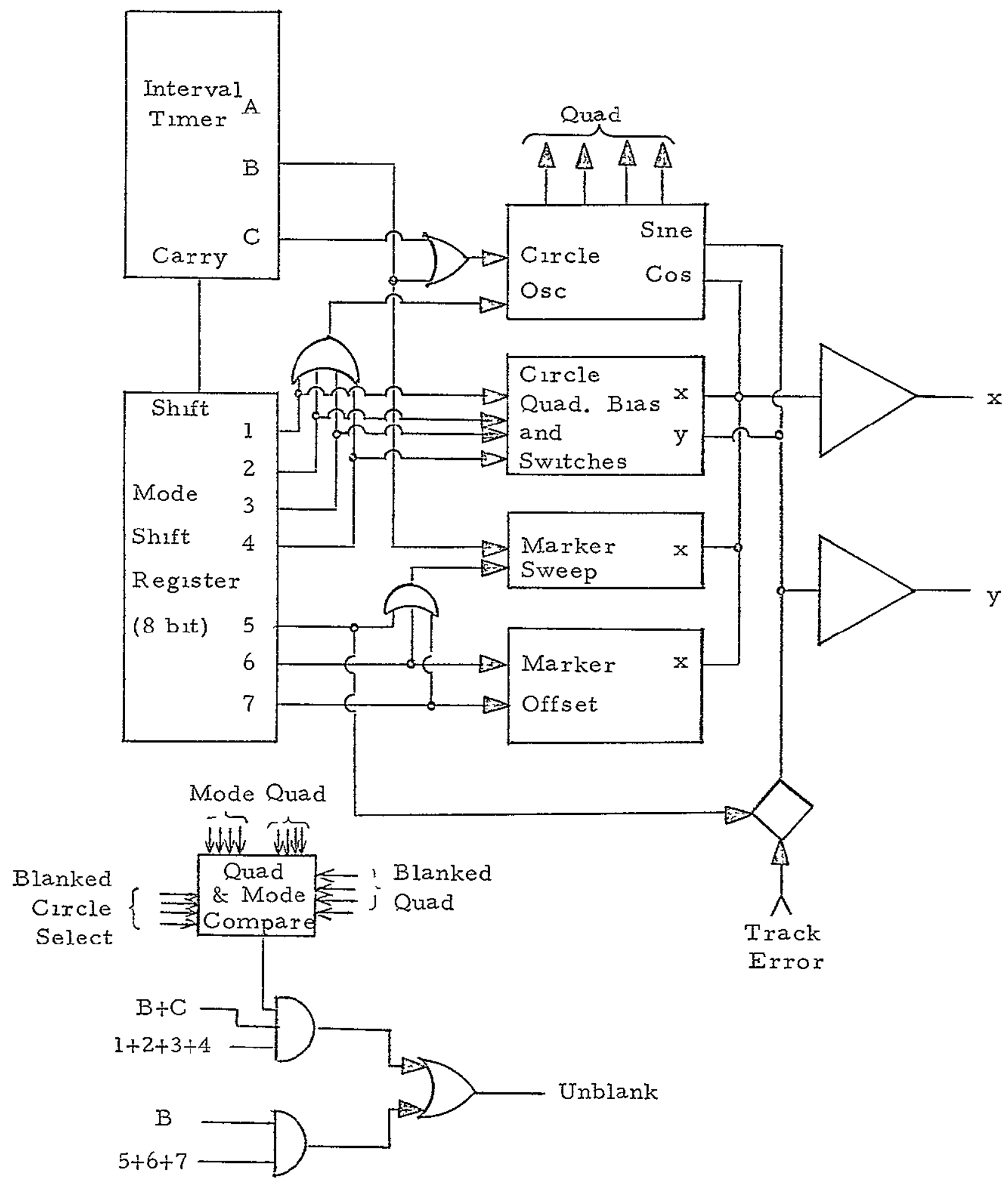

Figure B-2 Symbol generator block diagram 

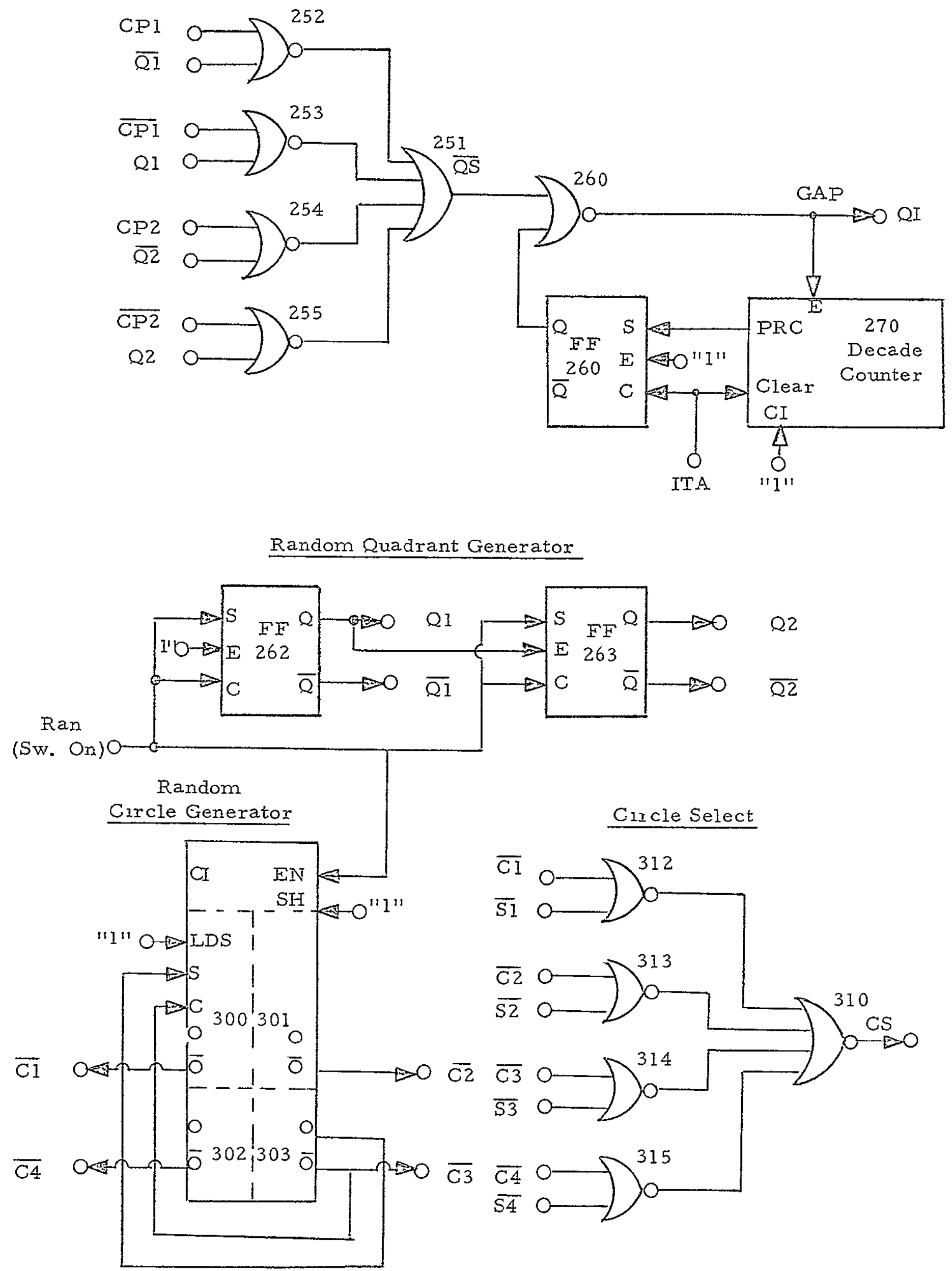

Figure B-3 Symbol logic diagram 


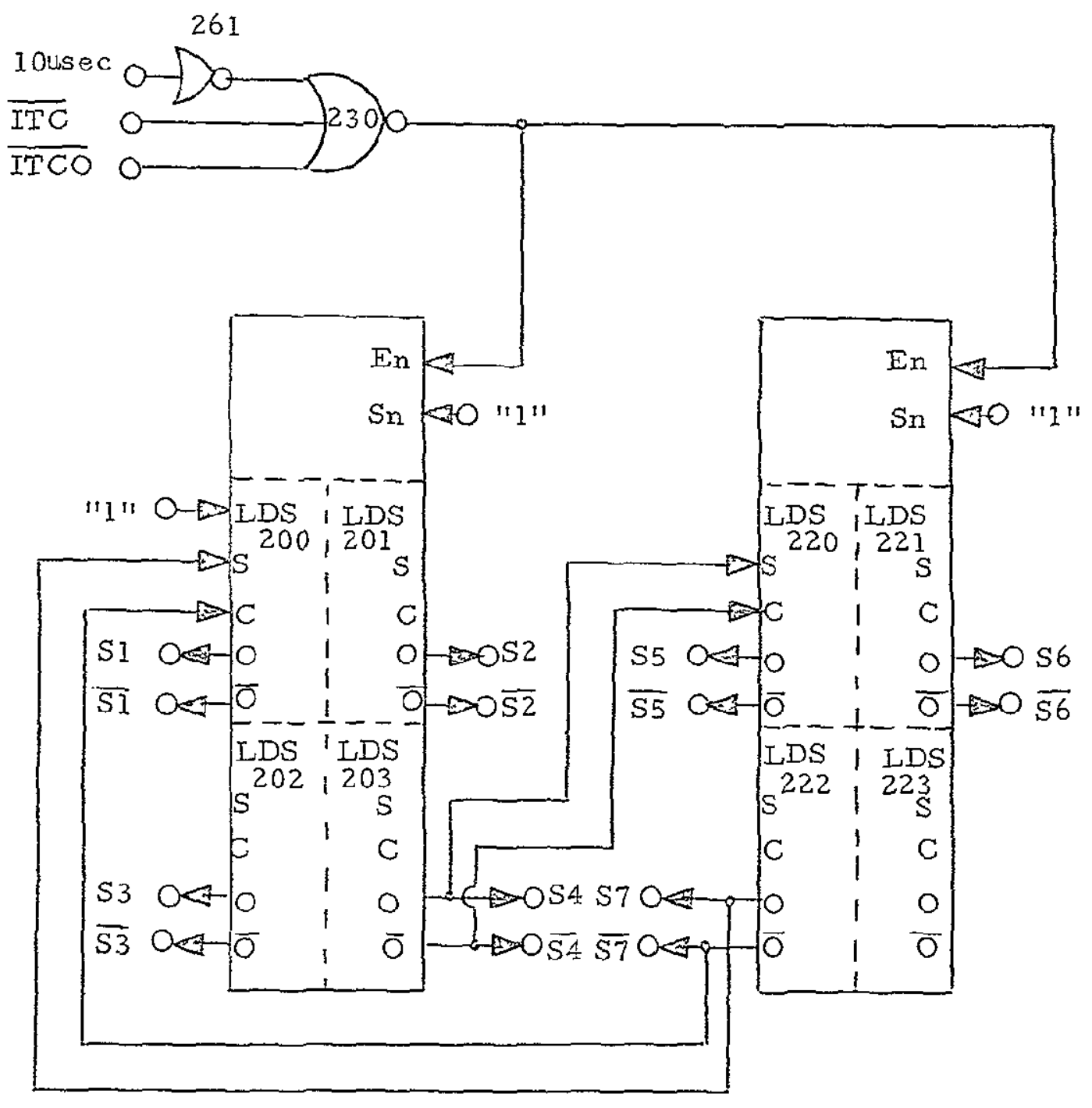

Figure B-4. Symbol generator state register (7 bit shift register), This shift register shifts at the end of each $C$ interval 


\begin{tabular}{|c|c|c|c|c|c|}
\hline$\overbrace{\text { State-Interval }}^{\text {Selection }}$ & & $\begin{array}{r}\text { Unblank } \\
1\end{array}$ & $\begin{array}{c}\text { Generator } \\
\text { Select }\end{array}$ & $\begin{array}{l}\text { Integrator } \\
\text { Mode }\end{array}$ & $\begin{array}{l}\text { Position } \\
\text { Select } \\
\text { Y-X }\end{array}$ \\
\hline & A & 0 & C & $\mathrm{R}$ & $U-I$ \\
\hline 1 & $\mathrm{~B}$ & 1 & $\mathrm{C}$ & 0 & $\mathrm{U}-\mathrm{L}$ \\
\hline (Circle) & $\mathrm{C}$ & $\mathrm{O}$ & $C$ & $\mathrm{R}$ & $\bar{U}-\mathrm{L}$ \\
\hline & A & 0 & C & $\mathrm{R}$ & $U-R$ \\
\hline 2 & $\mathrm{~B}$ & 1 & C & 0 & $\mathrm{U}-\mathrm{R}$ \\
\hline (Curcle) & $\mathrm{C}$ & $\mathrm{O}$ & C & $\mathrm{R}$ & $\bar{U}-\mathrm{R}$ \\
\hline & A & 0 & $\mathrm{C}$ & $\mathrm{R}$ & $D-L$ \\
\hline 3 & $B$ & 1 & $C$ & $\mathrm{O}$ & $D-L$ \\
\hline (Circle) & $\mathrm{C}$ & 0 & $\mathrm{C}$ & $\mathrm{R}$ & $\overline{D-L}$ \\
\hline & A. & 0 & C & $\mathrm{R}$ & $D-R$ \\
\hline 4 & $B$ & 1 & $\mathrm{C}$ & $\mathrm{O}$ & $D-R$ \\
\hline (Cırcle) & C & $\mathrm{O}$ & C & $\mathrm{R}$ & $\mathrm{D}-\mathrm{R}$ \\
\hline & A & 0 & L & $\mathrm{R}$ & $E-C$ \\
\hline 5 & $B$ & 1 & L & 0 & $E-C$ \\
\hline (Left Horizon) & $\mathrm{C}$ & 1 & L & $\mathrm{O}$ & $E-C$ \\
\hline & A & 0 & $L$ & $\mathrm{H}$ & $E-C$ \\
\hline 6 & $\mathrm{~B}$ & I & $I$ & $\mathrm{O}$ & $E-C$ \\
\hline (Right Horizon) & C & 1 & I & 음 & $E-C$ \\
\hline & A & $\mathrm{O}$ & I & $\mathrm{R}$ & $\mathrm{C}-\mathrm{C}$ \\
\hline 7 & $B$ & 1 & I & $\mathrm{O}$ & $\mathrm{C}-\mathrm{C}$ \\
\hline (Marker) & C & 0 & $\mathrm{~L}$ & $\mathrm{R}$ & $\mathrm{C}-\mathrm{C}$ \\
\hline
\end{tabular}

Generator Select $\quad C=$ Circle, $L=$ Line Segment

Integrator Mode $\quad \mathrm{R}$ = Reset, $\mathrm{O}=$ Operate, $\mathrm{H}=$ Fold

Position Select $\quad U=U p, D=$ Down, $L=$ Left, $R=R i g h t, C=$ Center, $\mathrm{E}=$ Error

Figure B-5 State switching matrix. 


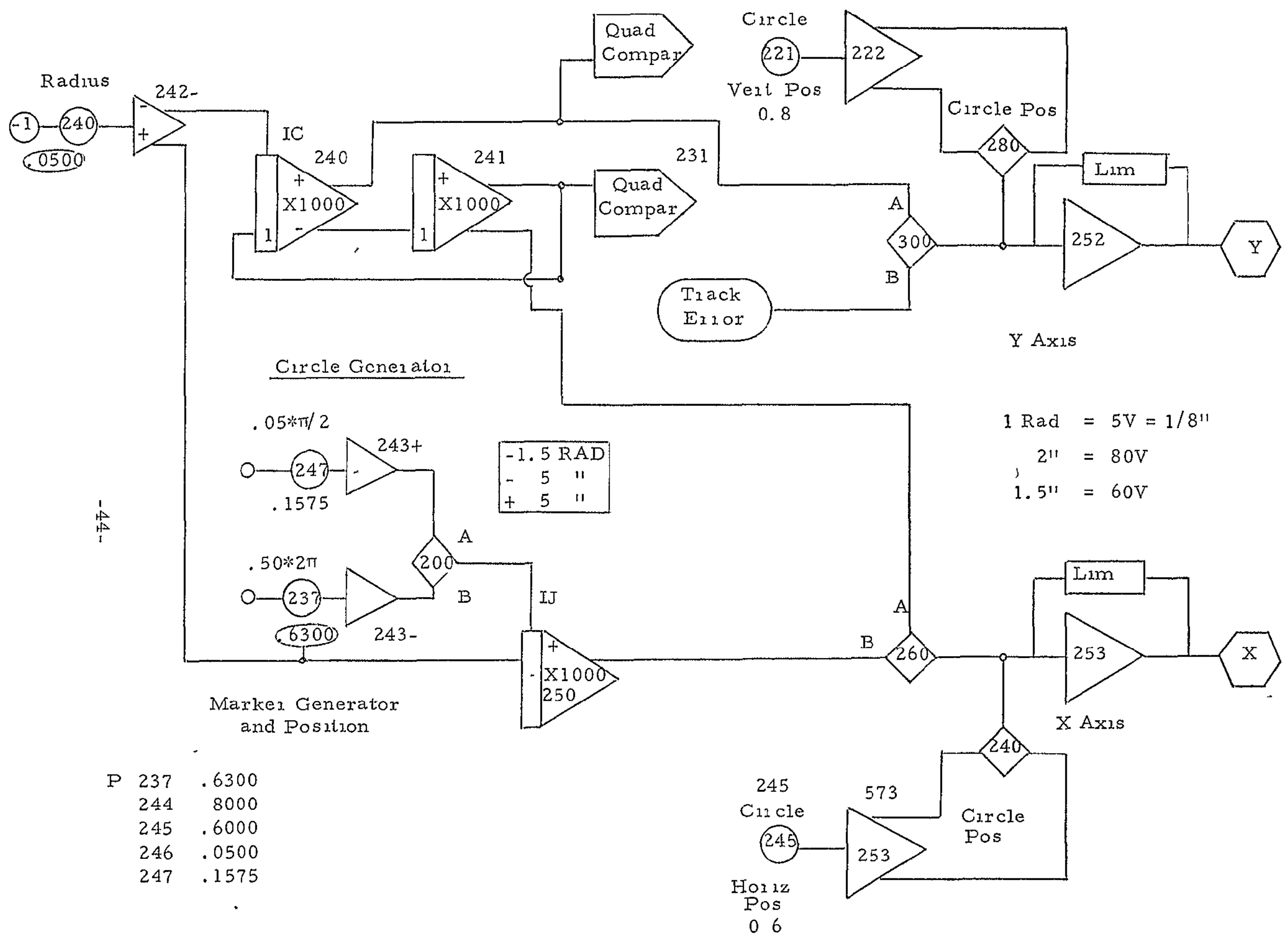

Figure B-6. Symbol generator analog diaglam. 
Switches and Comparator

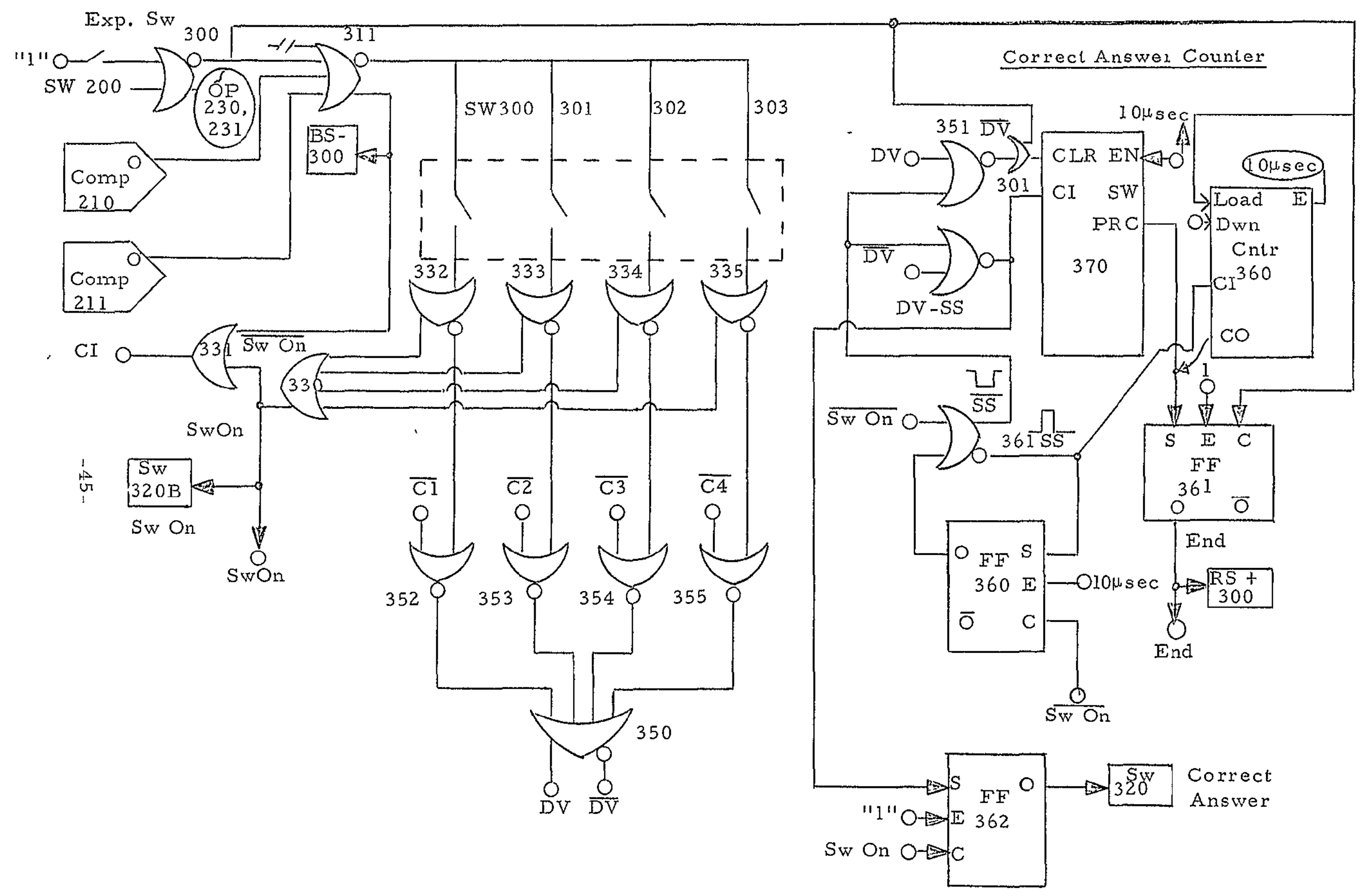

Figure B-7 Contiol logic diagiam. 

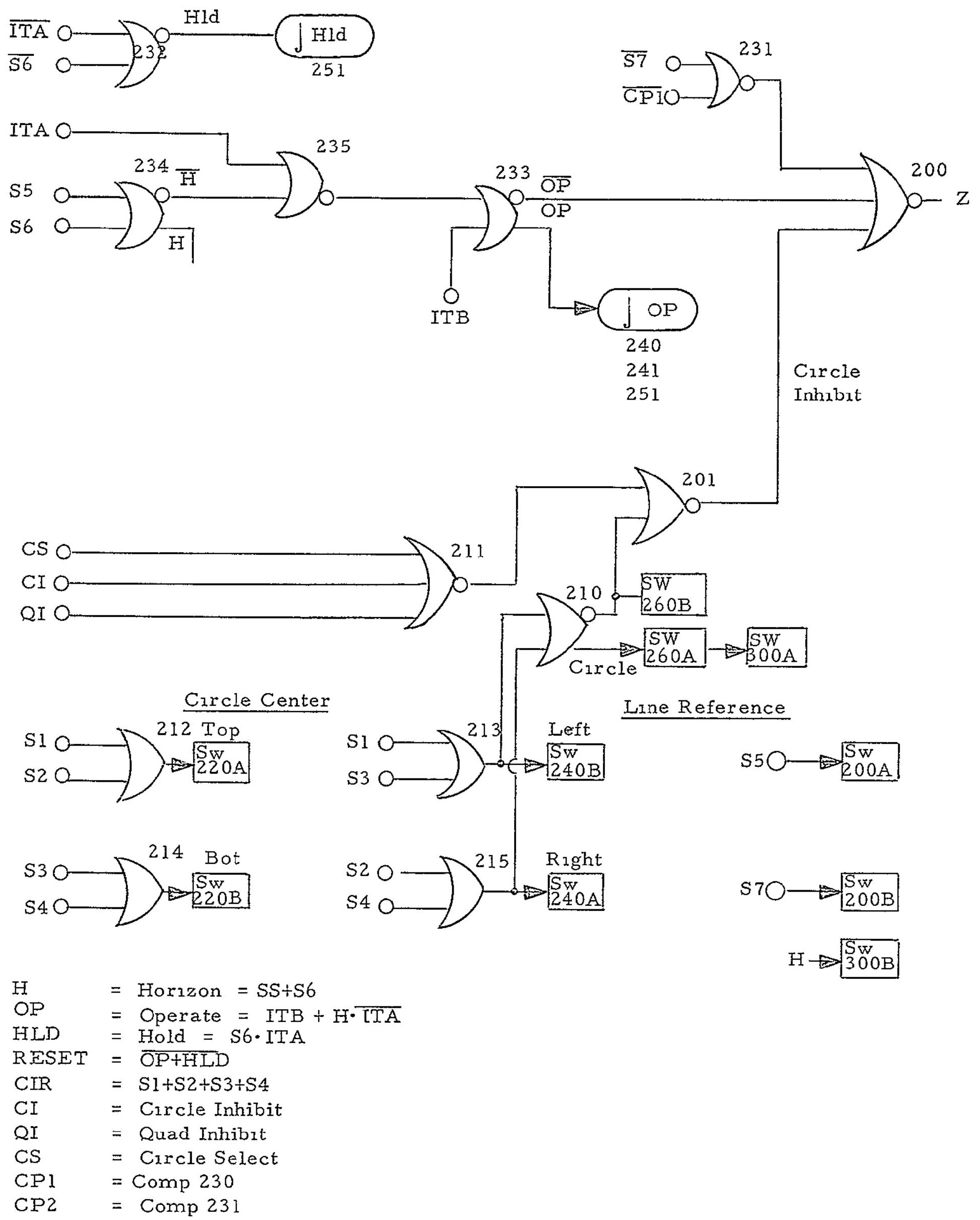

Figure B-8. Control logic diagram 


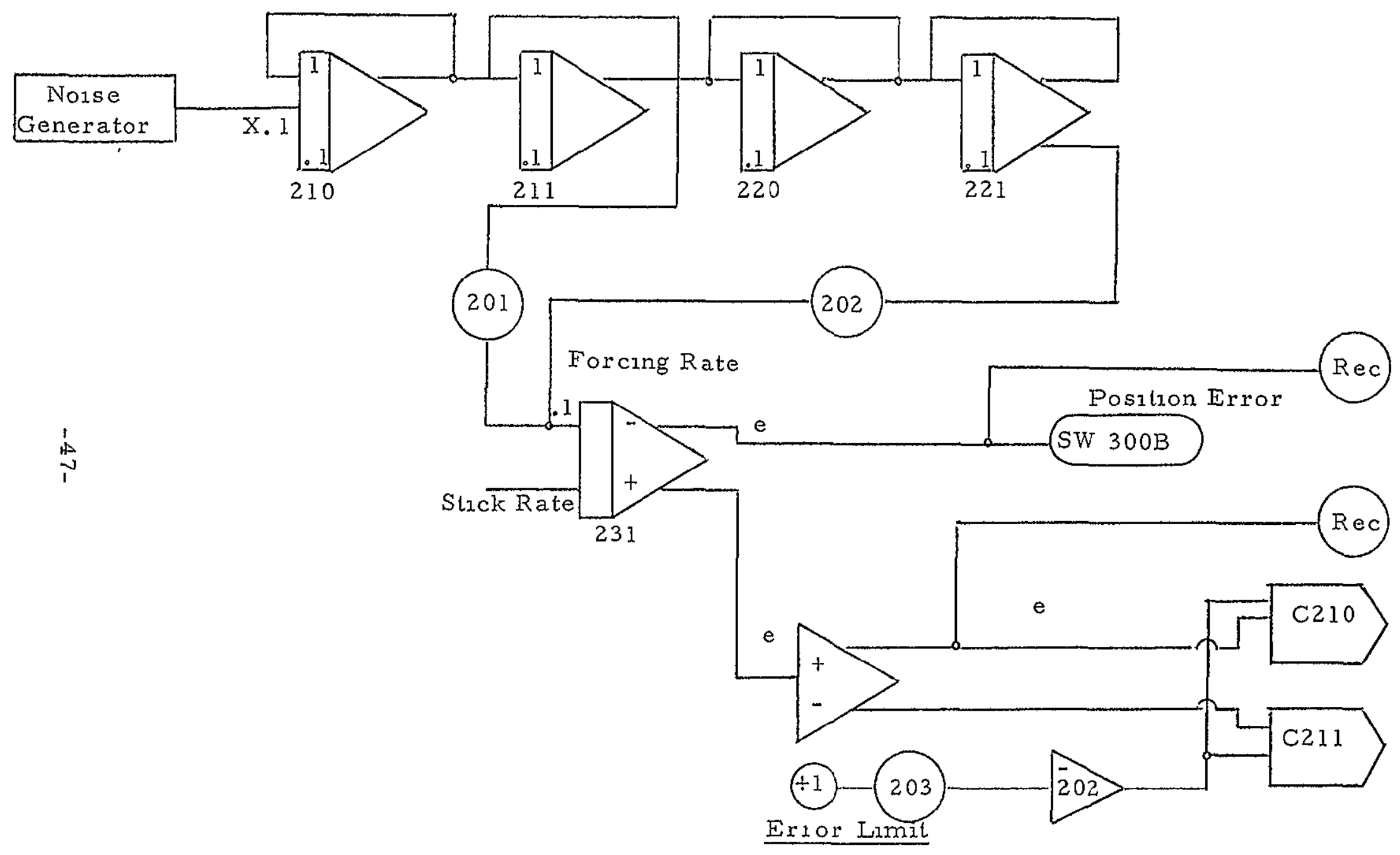

Figure B-9. Trackıng system analog diagram. 
APPENDIX $C$

BRIGHTNESS AND ANODE CURRENT TRANSFER FUNCTION 


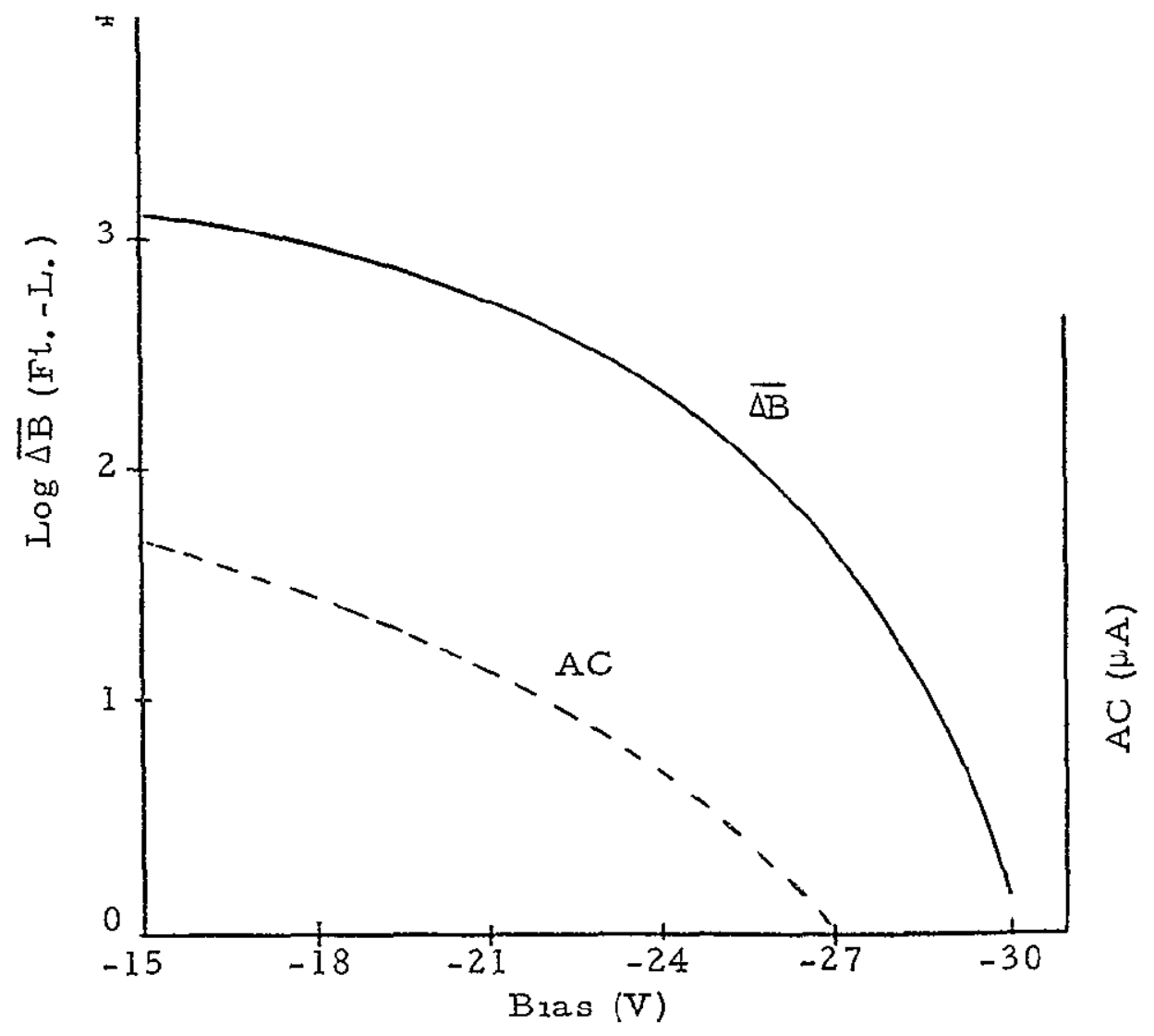

Figure C-1. Westinghouse mean trace brightness $(\Delta B)$ and anode current (AC) vs G1 bias.

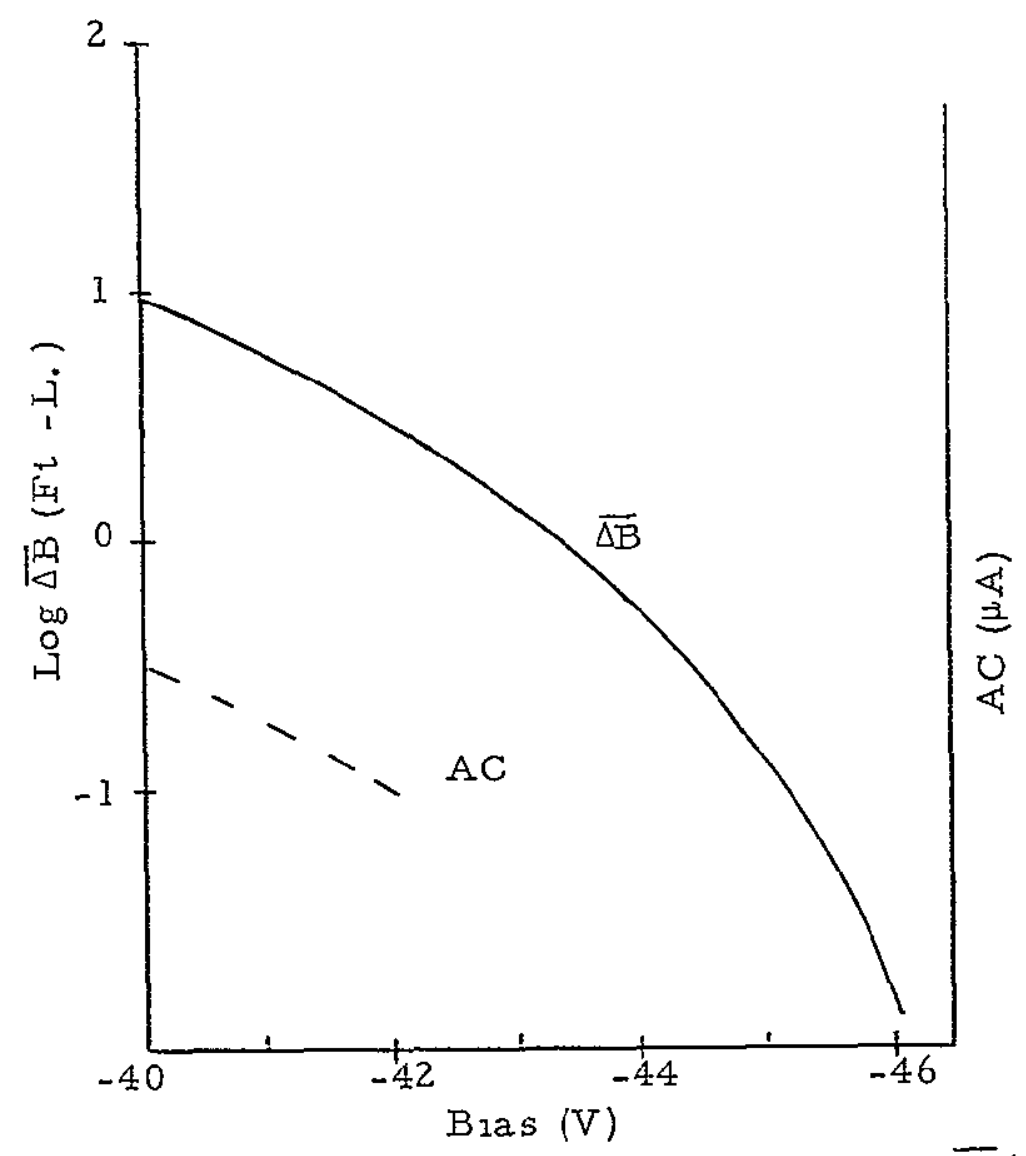

Figure C-2. Electro Vision mean trace brightness $(\overline{\Delta B})$ and anode current (AC) vs G1 bras. $-49-$ 


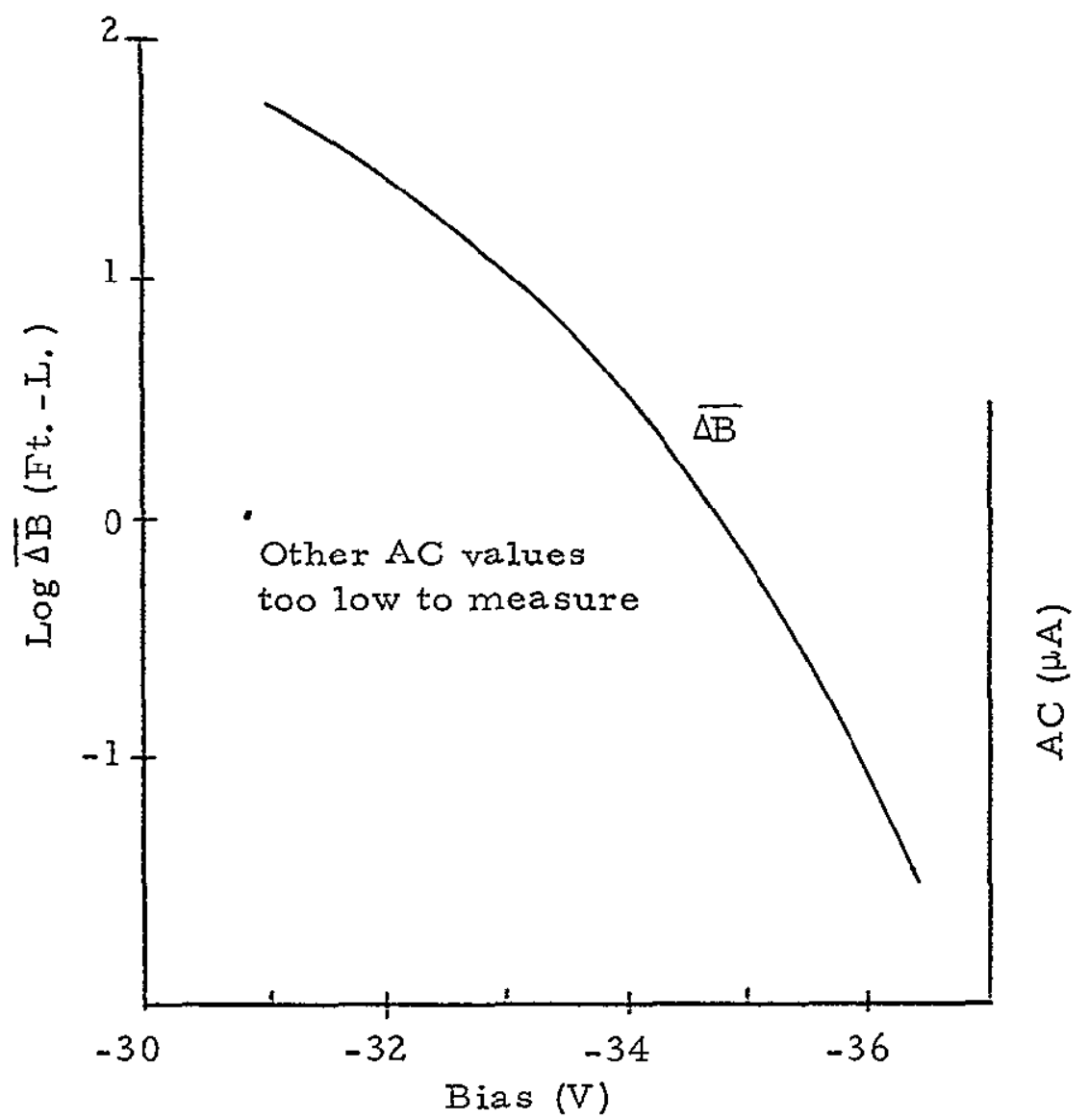

Figure C-3 Farman - mean trace brightness ( $\overline{\Delta B}$ ) and anode current (AC) vs GI buas.

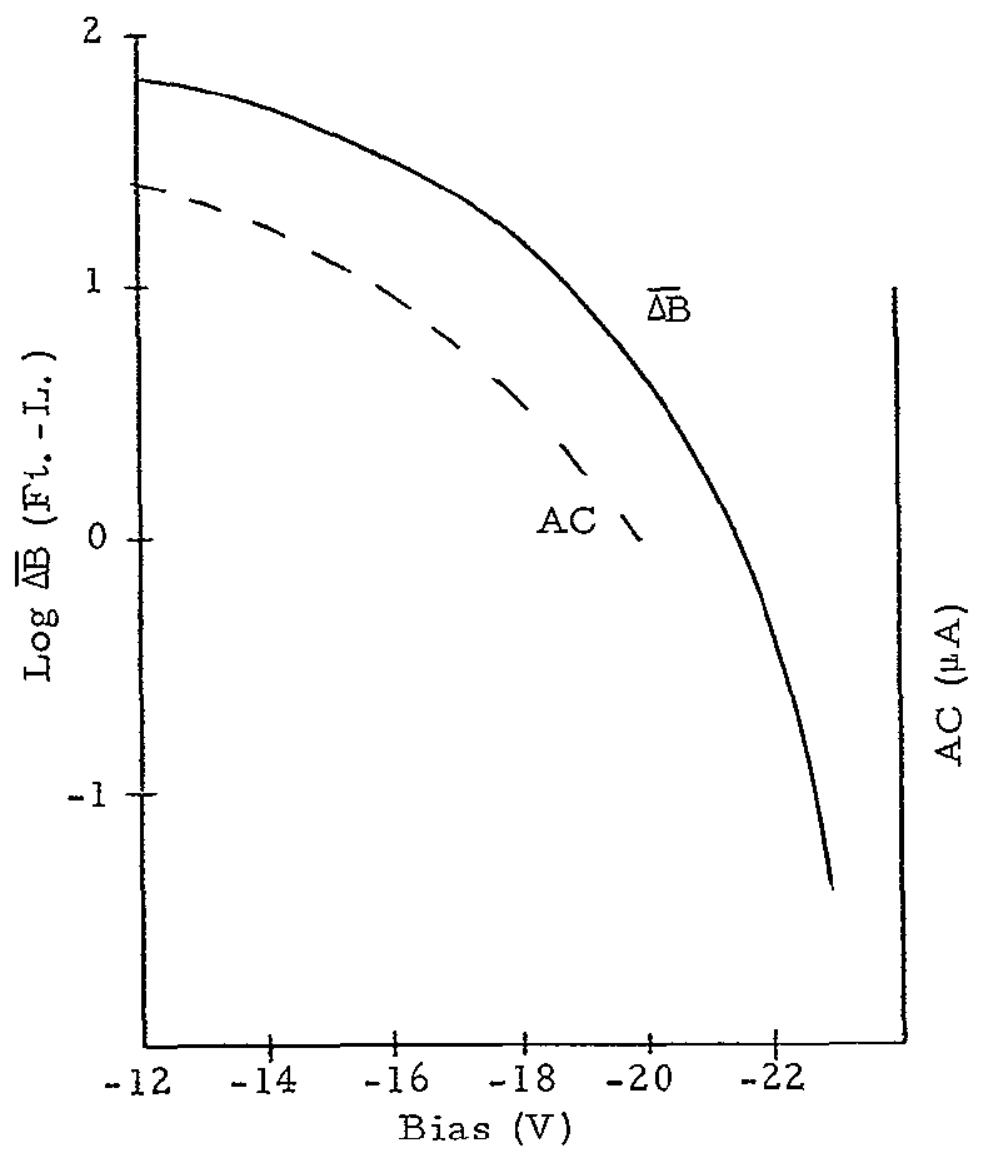

Figure C-4 Faırchild: mean trace brightness $(\overline{\Delta B})$ and anode current (AC) vs GI bias 
TABLE $\mathrm{C}-1$

Westunghouse: Figure Brightness, $\Delta B$, (ft. - L.)

\begin{tabular}{|c|c|c|c|c|c|c|}
\hline \multirow{2}{*}{$\begin{array}{l}\text { Gl Bias } \\
\text { (Volts) }\end{array}$} & \multicolumn{5}{|c|}{ Gap Position } & \multirow{2}{*}{$\begin{array}{c}\text { Anode } \\
\text { Cul } 1 \text { cnt } \\
\left(\begin{array}{ll}\mu \mathrm{A} .\end{array}\right)\end{array}$} \\
\hline & 1 & 2 & 3 & 4 & $\overline{\Delta \bar{B}}$ & \\
\hline \multirow[t]{3}{*}{30.00} & 1.90 & 2.70 & 2.85 & 1.90 & 2.21 & $*$ \\
\hline & 1.70 & 1.90 & 2.55 & 2.40 & & \\
\hline & 1.80 & 1.90 & 2.90 & 2.05 & & \\
\hline \multirow[t]{3}{*}{29.00} & 9.50 & 10.5 & 13.5 & 10.5 & 12.2 & $*$ \\
\hline & 9.00 & 10.5 & 15.0 & 15.0 & & \\
\hline & 9.50 & 13.0 & 15.5 & 11.5 & & \\
\hline \multirow[t]{3}{*}{28.00} & 28.0 & 34.0 & 42.0 & 48.0 & 38.5 & $*$ \\
\hline & 31.0 & 46.0 & 43.0 & 38.0 & & \\
\hline & 32.0 & 34.0 & 48.0 & 38.0 & & \\
\hline \multirow[t]{3}{*}{$27.00^{\&}$} & 50.0 & 68.0 & 88.0 & 92.0 & 71.8 & 1.0 \\
\hline & 50.0 & 82.0 & 92.0 & 56.0 & & \\
\hline & 74.0 & 70.0 & 84.0 & 56.0 & & \\
\hline \multirow[t]{3}{*}{26.00} & 115 & 95.0 & 115 & 75.0 & 100 & 1.5 \\
\hline & 100 & 100 & 100 & 80.0 & & \\
\hline & 110 & 85.0 & 120 & 105 & & \\
\hline \multirow[t]{3}{*}{25.00} & 155 & 200 & 230 & 190 & 199 & 3.0 \\
\hline & 165 & 220 & 200 & 200 & & \\
\hline & 210 & 200 & 210 & 210 & & \\
\hline \multirow[t]{3}{*}{24.00} & 245 & 320 & 380 & 340 & 308 & 4.5 \\
\hline & 220 & 360 & 360 & 280 & & \\
\hline & 265 & 320 & 300 & 300 & & \\
\hline \multirow[t]{3}{*}{23.00} & 400 & 440 & 480 & 440 & 437 & 7.0 \\
\hline & 400 & 460 & 500 & 400 & & \\
\hline & 360 & 460 & 500 & 400 & & \\
\hline \multirow[t]{3}{*}{22.00} & 540 & 540 & 780 & 640 & 615 & 9.5 \\
\hline & 500 & 580 & 680 & 620 & & \\
\hline & 600 & 620 & 700 & 580 & & \\
\hline \multirow[t]{3}{*}{21.00} & 540 & 720 & 820 & 700 & 733 & 12.0 \\
\hline & 580 & 760 & 820 & 780 & & \\
\hline & 560 & 780 & 840 & 900 & & \\
\hline \multirow[t]{3}{*}{18.00} & 920 & 1000 & 1000 & 950 & 1020 & 27.5 \\
\hline & 900 & 1050 & 1100 & 1000 & & \\
\hline & 1000 & 1100 & 1150 & 1100 & & \\
\hline \multirow[t]{3}{*}{15.00} & 1050 & 1350 & 1450 & 1600 & 1380 & 49.0 \\
\hline & 1200 & 1300 & 1450 & 1450 & & \\
\hline & 1200 & 1300 & 1600 & 1650 & & \\
\hline
\end{tabular}

* Anode Current <0. $\mu \mathrm{A}$. 
TABIE C-2

Westinghouse: Reflectance, R, (\%) and Background Brightness, B, (ft.-L.)

\begin{tabular}{|c|c|c|c|c|c|c|}
\hline \multirow{4}{*}{$\begin{array}{l}\text { Ambient } \\
\left(f_{0}-c_{0}\right)\end{array}$} & \multirow[b]{4}{*}{ Surface } & \multicolumn{5}{|c|}{ Light Position } \\
\hline & & \multicolumn{2}{|c|}{$30^{\circ}$} & \multicolumn{3}{|c|}{$60^{\circ}$} \\
\hline & & \multicolumn{5}{|c|}{ Observer Position, } \\
\hline & & $0^{\circ}$ & $-45^{\circ}$ & $30^{\circ}$ & $0^{\circ}$ & $-45^{\circ}$ \\
\hline \multirow[t]{3}{*}{$10,000^{8}$} & Paper & 8,000 & 8,600 & 8,000 & 3,600 & 4,600 \\
\hline & CRT & 7,300 & 7,500 & 7,400 & 3,000 & 3,500 \\
\hline & $\mathrm{R}(\%)$ & 73 & 70 & 74 & 67 & 61 \\
\hline \multirow[t]{3}{*}{5,000} & Paper & 4,000 & & & & \\
\hline & CRT & 3,700 & & & & \\
\hline & $\mathrm{R}(\%)$ & 74 & & & & \\
\hline \multirow[t]{3}{*}{1,000} & Paper & 800 & & & & \\
\hline & CRT & 720 & & & & \\
\hline & $R(\%)$ & 72 & & & & \\
\hline \multirow[t]{3}{*}{100} & Paper & 80.0 & & & & \\
\hline & $\mathrm{CRT}$ & 74.0 & & & & \\
\hline & $\mathrm{R}(\%)$ & 74 & & & & \\
\hline
\end{tabular}


TABLE $C-3$

Electro Vision: Figure Brightness, $\Delta B$, (ft. - L.)

\begin{tabular}{|c|c|c|c|c|c|c|}
\hline \multirow{2}{*}{$\begin{array}{l}\text { Gl Bias } \\
\text { (Volts) }\end{array}$} & \multicolumn{5}{|c|}{ Gap Position } & \multirow{2}{*}{$\begin{array}{c}\text { Anode } \\
\text { Cuxrent } \\
\left(\mu A_{.}\right)\end{array}$} \\
\hline & 1 & 2 & 3 & 4 & $\overline{\Delta \bar{B}}$ & \\
\hline 46.00 & $\begin{array}{l}.160 \\
.120 \\
.140\end{array}$ & $\begin{array}{r}.140 \\
.140 \\
.140\end{array}$ & $\begin{array}{r}.140 \\
.130 \\
.200\end{array}$ & $\begin{array}{l}.150 \\
.140 \\
.120\end{array}$ & .143 & $*$ \\
\hline 45.00 & $\begin{array}{l}1.25 \\
1.25 \\
1.00\end{array}$ & $\begin{array}{l}1.10 \\
1.15 \\
1.10\end{array}$ & $\begin{array}{l}1.35 \\
.950 \\
1.20\end{array}$ & $\begin{array}{l}1.10 \\
1.25 \\
1.05\end{array}$ & 1.15 & $*$ \\
\hline 44.00 & $\begin{array}{r}5.40 \\
4.60 \\
5.2\end{array}$ & $\begin{array}{l}4.80 \\
5.00 \\
4.60\end{array}$ & $\begin{array}{l}4.60 \\
4.00 \\
4.30\end{array}$ & $\begin{array}{l}5.40 \\
4.60 \\
4.60\end{array}$ & 4.76 & $*$ \\
\hline 43.00 & $\begin{array}{l}16.0 \\
14.5 \\
15.0\end{array}$ & $\begin{array}{l}13.0 \\
14.0 \\
13.0\end{array}$ & $\begin{array}{l}11.5 \\
13.0 \\
14.5\end{array}$ & $\begin{array}{l}15.0 \\
13.0 \\
12.5\end{array}$ & 13.8 & $*$ \\
\hline 42.00 & $\begin{array}{l}34.0 \\
30.0 \\
34.0\end{array}$ & $\begin{array}{l}30.0 \\
32.0 \\
28.0\end{array}$ & $\begin{array}{l}30.0 \\
30.0 \\
26.0\end{array}$ & $\begin{array}{l}29.0 \\
28.0 \\
34.0\end{array}$ & 30.4 & 1. 0 \\
\hline 41.00 & $\begin{array}{l}54.0 \\
46.0 \\
46.0\end{array}$ & $\begin{array}{l}48.0 \\
54.0 \\
48.0\end{array}$ & $\begin{array}{l}56.0 \\
48.0 \\
52.0\end{array}$ & $\begin{array}{l}50.0 \\
50.0 \\
53.0\end{array}$ & 50.4 & 1.5 \\
\hline 40.00 & $\begin{array}{l}74.0 \\
70.0 \\
74.0\end{array}$ & $\begin{array}{l}68.0 \\
74.0 \\
72.0\end{array}$ & $\begin{array}{l}82.0 \\
72.0 \\
80.0\end{array}$ & $\begin{array}{l}70.0 \\
74.0 \\
70.0\end{array}$ & 73.3 & 3.0 \\
\hline
\end{tabular}

Anode Current $<0.5 \mu \mathrm{A}$.

$\hat{2}$ 
TABLE C-4

Electro Vision: Reflectance, R, (\%) and Background Brightness, B, (ft.-L.)

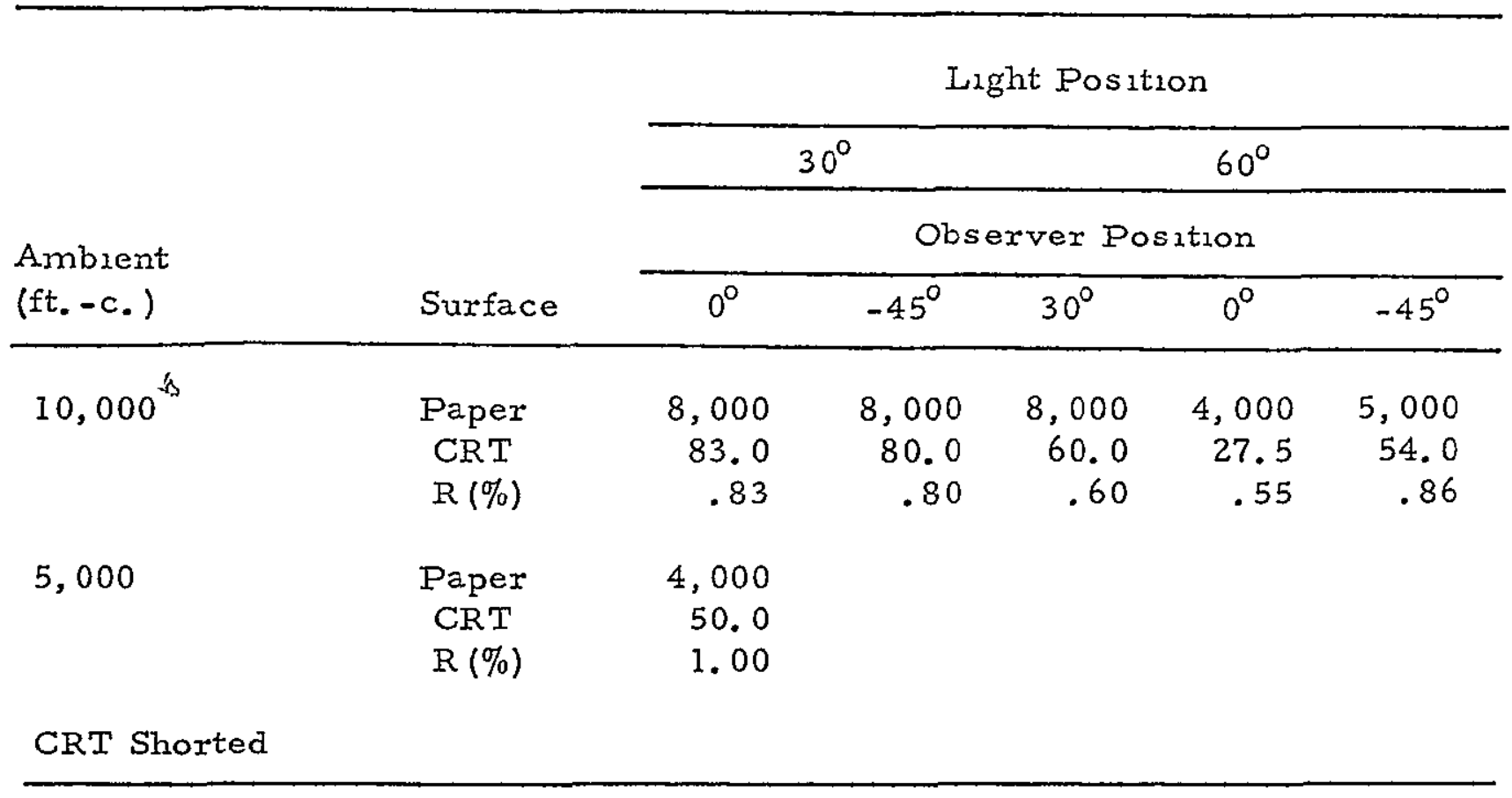


TABLE C-5

Hartman: Figure Brightness, $\Delta B$, (ft. - L.)

\begin{tabular}{|c|c|c|c|c|c|c|}
\hline \multirow{2}{*}{$\begin{array}{l}\text { GI Bras } \\
\text { (VoIts) }\end{array}$} & \multicolumn{5}{|c|}{ Gap Position } & \multirow{2}{*}{$\begin{array}{c}\text { Anode } \\
\text { Cuircit } \\
\left(\begin{array}{ll}\mu \text { A. }\end{array}\right)\end{array}$} \\
\hline & $I$ & 2 & 3 & 4 & $\overline{\Delta \mathrm{B}}$ & \\
\hline \multirow[t]{3}{*}{36.50} & .034 & .032 & .041 & .036 & .033 & $*$ \\
\hline & .032 & .030 & .040 & .030 & & \\
\hline & .028 & .030 & .038 & .026 & & \\
\hline \multirow[t]{3}{*}{36.00} & .115 & .120 & .120 & .140 & .115 & $*$ \\
\hline & .110 & .100 & .125 & .100 & & \\
\hline & .100 & .100 & .145 & .100 & & \\
\hline \multirow[t]{3}{*}{35.00} & .440 & .480 & .500 & .400 & .527 & $*$ \\
\hline & .380 & .560 & .860 & .500 & & \\
\hline & .340 & .500 & .540 & .820 & & \\
\hline \multirow[t]{3}{*}{34.50} & 1.50 & 1.30 & 1.35 & 1.20 & 1.45 & $*$ \\
\hline & 1.40 & 1.50 & 1.65 & 1.50 & & \\
\hline & 1.35 & 1.45 & 1.50 & 1.75 & & \\
\hline \multirow[t]{3}{*}{34.00} & 3.00 & 3.80 & 3.00 & 3.20 & 3.29 & $*$ \\
\hline & 3.20 & 3.60 & 3.80 & 3.60 & & \\
\hline & 2.60 & 3.70 & 2.80 & 3.20 & & \\
\hline \multirow[t]{3}{*}{33.00} & 13.0 & 13.5 & 16.0 & 12.5 & 13.3 & $*$ \\
\hline & 12.5 & 13.5 & 12.0 & 13.0 & & \\
\hline & 12.5 & 14.0 & 15.0 & 12.5 & & \\
\hline \multirow[t]{3}{*}{32.00} & 28.0 & 32.0 & 32.0 & 28.0 & 29.8 & $*$ \\
\hline & 27.0 & 30.0 & 30.0 & 26.0 & & \\
\hline & 24.0 & 32.0 & 34.0 & 34.0 & & \\
\hline \multirow[t]{3}{*}{31.00} & 50.0 & 60.0 & 66.0 & 60.0 & 55.3 & 1. 0 \\
\hline & 52.0 & 60.0 & 60.0 & 40.0 & & \\
\hline & 46.0 & 62.0 & 64.0 & 44.0 & & \\
\hline
\end{tabular}

*Anode Current $<0.5 \mu \mathrm{A}$. 
TABLE C-6

Hartman: Reflectance, R, (\%) and Background Brightness, B, (ft.-L.)

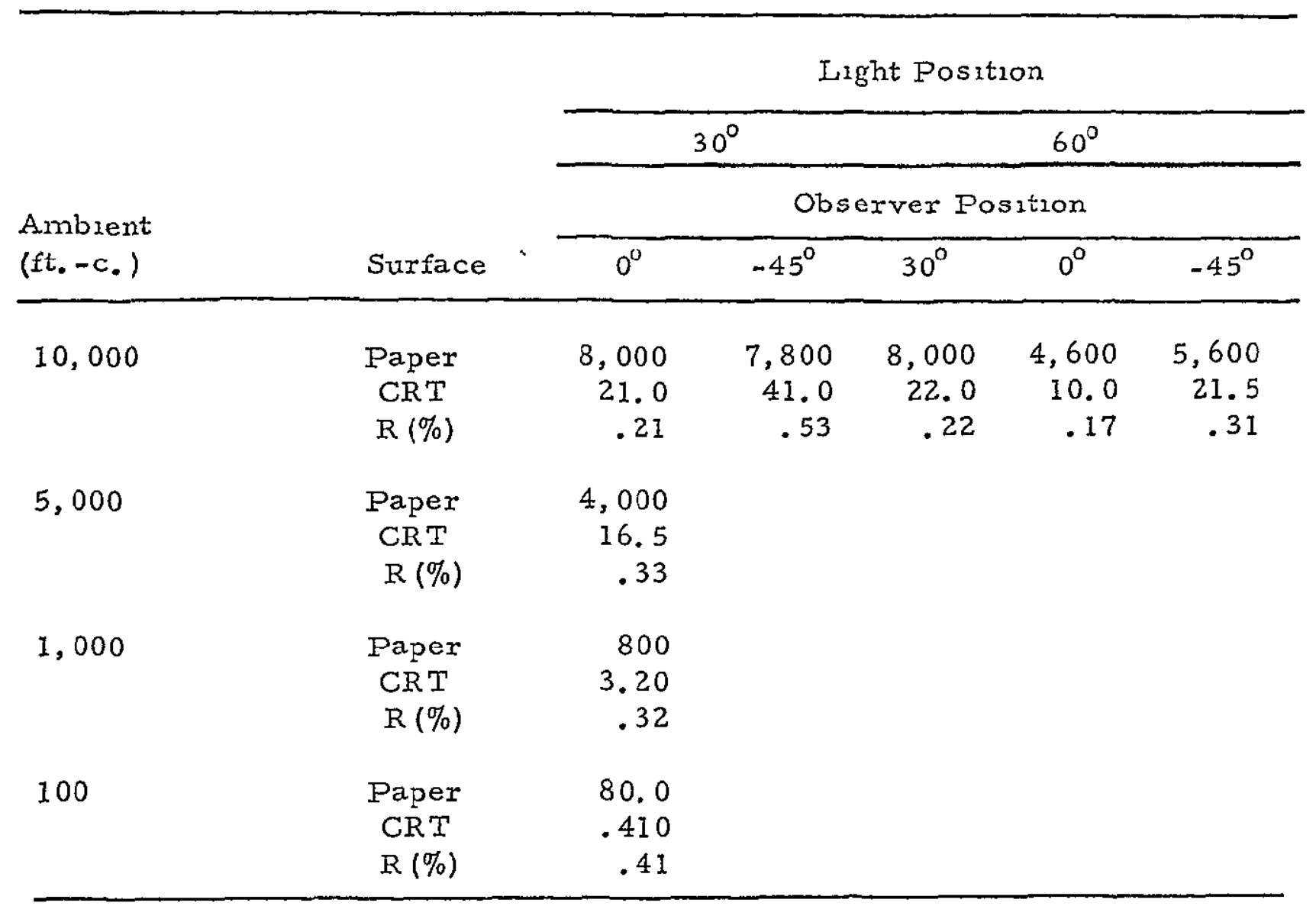


TABLE $\quad \mathrm{C}-7$

Fairchild: Figure Brightness, $\Delta B$, (ft. -L.)

\begin{tabular}{|c|c|c|c|c|c|c|}
\hline \multirow{2}{*}{$\begin{array}{l}\text { GI Bias } \\
\text { (Volts) }\end{array}$} & \multicolumn{5}{|c|}{ Gap Position } & \multirow{2}{*}{$\begin{array}{l}\text { Anode } \\
\text { Cul rent } \\
(\mu \mathrm{A} .)\end{array}$} \\
\hline & 1 & 2 & 3 & 4 & $\overline{\Delta \mathrm{B}}$ & \\
\hline \multirow[t]{3}{*}{23.00} & .045 & .035 & .034 & .035 & .040 & $*$ \\
\hline & .038 & .038 & .044 & .034 & & \\
\hline & .042 & .039 & .047 & .045 & & \\
\hline \multirow[t]{3}{*}{22.00} & .580 & .570 & .630 & .530 & .555 & $*$ \\
\hline & .580 & .500 & .620 & .650 & & \\
\hline & .440 & .500 & .500 & .560 & & \\
\hline \multirow[t]{2}{*}{21.00} & 1.60 & 2.20 & 2.50 & 2.20 & 2.24 & $*$ \\
\hline & 2.60 & 2.60 & 2.10 & 1.90 & & \\
\hline • & 2.50 & 2.10 & 2.80 & 1.80 & & \\
\hline \multirow[t]{3}{*}{20.00} & 5.80 & 5.00 & 6.20 & 5.40 & 5.70 & 1.0 \\
\hline & 5.80 & 5.40 & 5.80 & 5.20 & & \\
\hline & 5.20 & 4.80 & 7.00 & 6.80 & & \\
\hline \multirow[t]{3}{*}{19.00} & 13.0 & 11.0 & 12.0 & 9.50 & 11.4 & 2.5 \\
\hline & 12.5 & 9.50 & 13.0 & 10.5 & & \\
\hline & 11.5 & 10.5 & 11.0 & 12.5 & & \\
\hline \multirow[t]{3}{*}{18.00} & 18.0 & 14.0 & 16.0 & 18.0 & 16.4 & 4.5 \\
\hline & 19.0 & 15.0 & 16.0 & 15.5 & & \\
\hline & 17.0 & 15.0 & 18.0 & 15.5 & & \\
\hline \multirow[t]{3}{*}{17.00} & 26.0 & 23.0 & 20.0 & 21.0 & 22.5 & 7.5 \\
\hline & 24.0 & 21.0 & 19.5 & 22.0 & & \\
\hline & 22.0 & 23.0 & 22.5 & 26.0 & & \\
\hline \multirow[t]{3}{*}{16.00} & 32.0 & 28.0 & 28.0 & 28.0 & 28.8 & 11.0 \\
\hline & 30.0 & 26.0 & 27.0 & 32.0 & & \\
\hline & 30.0 & 28.0 & 30.0 & 27.0 & & \\
\hline \multirow[t]{3}{*}{14.00} & 44.0 & 40.0 & 40.0 & 34.0 & 40.1 & 21.5 \\
\hline & 42.0 & 42.0 & 38.0 & 36.0 & & \\
\hline & 43.0 & 41.0 & 42.0 & 39.0 & & \\
\hline \multirow[t]{3}{*}{12.00} & 48.0 & 48.0 & 51.0 & 52.0 & 48.8 & 38.0 \\
\hline & 48.0 & 47.0 & 50.0 & 46.0 & & \\
\hline & 47.0 & 47.0 & 54.0 & 48.0 & & \\
\hline
\end{tabular}

* Anode Current $<0.5 \mu \mathrm{A}$. 
TABLE C-8

Fairchild: Reflectance, R, (\%) and Background Brightness, B, (ft.-L.)

\begin{tabular}{|c|c|c|c|c|c|c|}
\hline \multirow{4}{*}{$\begin{array}{l}\text { Ambient } \\
\text { (ft. - c.) }\end{array}$} & \multirow[b]{4}{*}{ Surface } & \multicolumn{5}{|c|}{ Light Position } \\
\hline & & \multicolumn{2}{|c|}{$30^{\circ}$} & \multicolumn{3}{|c|}{$60^{\circ}$} \\
\hline & & \multicolumn{5}{|c|}{ Observer Position } \\
\hline & & $0^{\circ}$ & $-45^{\circ}$ & $30^{\circ}$ & $0^{\circ}$ & $-45^{\circ}$ \\
\hline \multirow[t]{3}{*}{10,000} & Paper & 8,000 & 8,800 & 8,000 & 3,700 & 5,000 \\
\hline & $\mathrm{CRT}$ & 245 & 270 & 240 & 98.0 & 190 \\
\hline & $R(\%)$ & 2.4 & 2.4 & 2.4 & 2.1 & 3.0 \\
\hline \multirow[t]{3}{*}{5,000} & Paper & 4,000 & & & & \\
\hline & CRT & 135 & & & & \\
\hline & $\mathrm{R}(\%)$ & 2.7 & & & & \\
\hline \multirow[t]{3}{*}{1,000} & Paper & 800 & & & & \\
\hline & CRT & 28.0 & & & & \\
\hline & $\mathrm{R}(\%)$ & 2.8 & & & & \\
\hline \multirow[t]{3}{*}{100} & Paper & 80.0 & & & & \\
\hline & $\mathrm{CRT}$ & 2.80 & & & & \\
\hline & $\mathrm{R}(\%)$ & 2.8 & & & & \\
\hline
\end{tabular}




\section{APPENDIX D}

DETECTION THRESHOLDS AND WORKING LEVEL PREFERENCES

AS A FUNCTION OF AMBIENT ILLUMINATION 


\section{TABLE D-1}

Westinghouse: Detection Thresholds and Preferred Working Levels (Volts) At 10,000 ft. -c. Ambient

\begin{tabular}{|c|c|c|c|c|c|c|}
\hline \multirow[b]{4}{*}{ Observer } & & \multirow{4}{*}{$\begin{array}{c}\text { Working } \\
\text { Preference* } \\
\text { (Volts) }\end{array}$} & \multicolumn{4}{|c|}{ Light Position } \\
\hline & & & \multicolumn{2}{|c|}{$30^{\circ}$} & \multicolumn{2}{|c|}{$60^{\circ}$} \\
\hline & & & \multicolumn{4}{|c|}{ Observer Position } \\
\hline & & & $0^{\circ}$ & $-45^{\circ}$ & $0^{\circ}$ & $-45^{\circ}$ \\
\hline $\mathrm{MC}$ & \multirow{5}{*}{1} & 15.20 & 23.40 & 22.10 & 26.30 & 24.90 \\
\hline RK & & 15.19 & 23.50 & 23.20 & 26.60 & 26.30 \\
\hline WK & & 15.78 & 23.50 & 22.20 & 26.20 & 25.70 \\
\hline $\mathrm{BB}$ & & 17.50 & 22.90 & 22.30 & 26.00 & 26.00 \\
\hline $\bar{V}$ & & 15.92 & 23.33 & 22.45 & 26.28 & 25.73 \\
\hline$\overline{\Delta \mathrm{B}}\left(\mathrm{ft} .-\mathrm{L}_{\bullet}\right)$ & & 1,250 & 400 & 540 & 110 & 145 \\
\hline$A C\left(\mu A_{.}\right)$ & & 40.0 & 6.0 & 8.5 & 1.5 & 2.0 \\
\hline$B\left(f t_{0}-I_{.}\right)$ & & 7,300 & 7,300 & 7,500 & 3,000 & 3,500 \\
\hline$\overline{\Delta B} / \mathrm{B}$ & & .171 & .055 & .072 & .037 & .041 \\
\hline
\end{tabular}

${ }^{*}$ Light Postion $=30^{\circ} ;$ Observer Position $=0^{\circ}$ 


\section{TABLE D-2}

Electro Vision: Detection Thresholds and Preferred Working Levels (Volts) At 10,000 ft. -c. Ambient

\begin{tabular}{|c|c|c|c|c|c|}
\hline \multirow[b]{4}{*}{ Observer } & \multirow{4}{*}{$\begin{array}{l}\text { Working } \\
\text { Preference* } \\
\text { (Volts) }\end{array}$} & \multicolumn{4}{|c|}{ Light Position } \\
\hline & & \multicolumn{2}{|c|}{$30^{\circ}$} & \multicolumn{2}{|c|}{$60^{\circ}$} \\
\hline & & \multicolumn{4}{|c|}{ Observer Position } \\
\hline & & $0^{\circ}$ & $-45^{\circ}$ & $0^{\circ}$ & $-45^{\circ}$ \\
\hline $\mathrm{MC}$ & 41.65 & 44.50 & 44.20 & 44.70 & 44.50 \\
\hline RK & 41.50 & 44.70 & 44.40 & 45.00 & 44.80 \\
\hline WK & 41.75 & 44.10 & 43.90 & 44.50 & 44.40 \\
\hline $\mathrm{BB}$ & 41.96 & 44.20 & 44.20 & 44.70 & 44.40 \\
\hline $\bar{V}$ & 41.72 & 44.38 & 44.18 & 44.73 & 44.53 \\
\hline$\overline{\Delta B}\left(\right.$ ft. $\left.-L_{.}\right)$ & 36.0 & 2.90 & 3.80 & 1.70 & 2.30 \\
\hline$\mu \mathrm{A}$ & 1.10 & $* * 6$ & 将决 & $* *$ & $* *$ \\
\hline$B\left(f t .-L_{.}\right)$ & 83.0 & 83.0 & 80.0 & 27.5 & 54.0 \\
\hline$\overline{\Delta \bar{B}} / \mathrm{B}$ & .434 & .035 & .048 & .062 & .038 \\
\hline
\end{tabular}


TABLE D-3

Hartman: Detection Thresholds and Preferred Working Levels (Volts)

At 10,000 ft. - L. Ambient

\begin{tabular}{|c|c|c|c|c|c|}
\hline \multirow[b]{4}{*}{ Observer } & \multirow{4}{*}{$\begin{array}{c}\text { Working } \\
\text { Preference* } \\
\text { (Volts) }\end{array}$} & \multicolumn{4}{|c|}{ Light Position } \\
\hline & & \multicolumn{2}{|c|}{$30^{\circ}$} & \multicolumn{2}{|c|}{$60^{\circ}$} \\
\hline & & \multicolumn{4}{|c|}{ Observer Position } \\
\hline & & $0^{\circ}$ & $-45^{\circ}$ & $0^{\circ}$ & $-45^{\circ}$ \\
\hline $\mathrm{MC}$ & 31.95 & 34.60 & 34.00 & 34.60 & 34.20 \\
\hline $\mathrm{RK}$ & 31.86 & 34.90 & 34.20 & 34.90 & 34.30 \\
\hline WK & 32.66 & 34.40 & 34.00 & 34.50 & 34.00 \\
\hline $\mathrm{BB}$ & 32.63 & 34.40 & 34.00 & 34.40 & 34.50 \\
\hline $\bar{V}$ & 32.28 & 34.58 & 34.05 & 34.60 & 34.25 \\
\hline$\overline{\Delta B}\left(\right.$ ft. $\left.-I_{\text {. }}\right)$ & 25.0 & 1.20 & 3.00 & 1.20 & 2.10 \\
\hline$\mu \mathrm{A}$ & $* *$ & $* *$ & 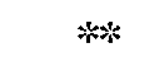 & $* *$ & $* *$ \\
\hline$B\left(\right.$ ft. $\left.-I_{.}\right)$ & 21.0 & 21.0 & 41.0 & 10.0 & 21.5 \\
\hline$\overline{\Delta B} / B$ & 1.19 & .057 & .073 & .120 & .098 \\
\hline
\end{tabular}

${ }^{*}$ Light Position $=30^{\circ} ;$ Observer Position $=0^{\circ}$

$* *$ Anode Current $<0.5 \mu \mathrm{A}$ 
TABIE D-4

Fairchild: Detection Thresholds and Preferred Working Levels (Volts) At 10,000 ft. - L. Ambient

\begin{tabular}{|c|c|c|c|c|c|}
\hline \multirow[b]{4}{*}{ Observer } & \multirow{4}{*}{$\begin{array}{l}\text { Working } \\
\text { Preference* } \\
\text { (Volts) }\end{array}$} & \multicolumn{4}{|c|}{ Light Position } \\
\hline & & \multicolumn{2}{|c|}{$30^{\circ}$} & \multicolumn{2}{|c|}{$60^{\circ}$} \\
\hline & & \multicolumn{4}{|c|}{ Observer Position } \\
\hline & & $0^{\circ}$ & $-45^{\circ}$ & $0^{\circ}$ & $-45^{\circ}$ \\
\hline $\mathrm{MC}$ & 11.74 & 19.20 & 18.60 & 20.50 & 19.90 \\
\hline RK & 14.72 & 19.40 & 18.90 & .20 .50 & 20.20 \\
\hline WK & 10.60 & 19.00 & 18.20 & 20.20 & 19.80 \\
\hline $\mathrm{BB}$ & 14.60 & 19.00 & 18.30 & 20.40 & 19.60 \\
\hline$\overline{\mathrm{V}}$ & 12.92 & 19.15 & 18.50 & 20.40 & 19.88 \\
\hline$\overline{\Delta B}\left(f t_{0}-L\right)$ & 45.0 & 10.0 & 14.0 & 4.00 & 6.20 \\
\hline$\mu \mathrm{A}$ & 28.0 & 2.0 & 3.5 & 米 & 1.0 \\
\hline$B(f t .-L)$ & 245 & 245 & 270 & 98.0 & 190 \\
\hline$\overline{\Delta \mathrm{B}} / \mathrm{B}$ & .184 & .041 & .052 & .041 & .033 \\
\hline
\end{tabular}

\footnotetext{
*Light Position $=30^{\circ} ;$ Observer Position $=0^{\circ}$ * Anode Current $<0.5 \mu \mathrm{A}$.
} 
TABIE D-5

Westinghouse: Detection Thresholds (Volts) vs. Ambient/Background Brightness. $\left(\right.$ Light Position $=30^{\circ} ;$ Observer Position $\left.=0^{\circ}\right)$

\begin{tabular}{|c|c|c|c|c|c|c|c|}
\hline \multirow{2}{*}{$\begin{array}{l}\begin{array}{l}\text { Ambient } \\
\left(\mathrm{ft} .-\mathrm{c}_{.}\right)\end{array} \\
10,000\end{array}$} & \multirow{2}{*}{$\frac{\mathrm{T}_{\mathrm{T}}^{\mathrm{I}}}{\mathrm{RK}}$} & \multirow{2}{*}{$\begin{array}{c}\begin{array}{c}\text { Detection } \\
\text { Threshold } \\
\text { (Volts) }\end{array} \\
23.50\end{array}$} & $\begin{array}{c}\text { Working } \\
\text { Preference } \\
\text { (Volts) }\end{array}$ & $\begin{array}{l}\text { Ambien } \\
(\text { ft. - c.) }\end{array}$ & \multicolumn{2}{|c|}{$\begin{array}{l}\text { Detection } \\
\text { Threshold } \\
\text { ) Observer (Volts) }\end{array}$} & $\begin{array}{l}\text { Working } \\
\text { Preference } \\
\text { (Volts) }\end{array}$ \\
\hline & & & 15.19 & 1,000 & RK & 28.90 & 26.00 \\
\hline & WK & 23.50 & 15.78 & & WK & 28.40 & 25.50 \\
\hline & $\mathrm{BB}$ & 22.90 & 17.50 & & $\mathrm{BB}$ & 28.50 & 25.19 \\
\hline & $\overrightarrow{\mathrm{V}}$ & 23.30 & 16.16 & & $\overline{\mathrm{V}}$ & 28.60 & 25.56 \\
\hline & $\overline{\Delta B}(f t .-L)$. & 400 & 1,210 & & $\overline{\Delta B}\left(\right.$ ft. $\left.-I_{0}\right)$ & ) 18.0 & 158 \\
\hline & $\mu A$ & 6.0 & 38.0 & & $\mu A$. & $*$ & 2.5 \\
\hline & $\mathrm{B}\left(\mathrm{fc},-I_{0}\right)$ & 7,300 & 7,300 & & $\mathrm{~B}$ (ft. - I. & .) 720 & 720 \\
\hline & $\overline{\Delta \bar{B}} / \mathrm{B}$ & .055 & .166 & & $\overline{\Delta \mathrm{B}} / \mathrm{B}$ & .025 & .219 \\
\hline \multirow[t]{8}{*}{5,000} & RK & 27.20 & 17.39 & 100 & $\mathrm{RK}$ & 30.00 & 28.10 \\
\hline & WK & 26.70 & 19.05 & & WK & 29.80 & 28.30 \\
\hline & $B B$ & 26.40 & 19.14 & & $\mathrm{BB}$ & 29.90 & 28.34 \\
\hline & $\overline{\mathrm{V}}$ & 26.77 & 18.53 & & $\overrightarrow{\mathrm{V}}$ & 29.90 & 28.25 \\
\hline & $\overline{\Delta B}\left(f t .-L_{.}\right)$ & 82.0 & 960 & & $\overline{\Delta B}$ (ft. - L. & 2.70 & 26.5 \\
\hline & $\mu \mathrm{A}$. & 1.50 & 24.00 & & $\mu$ A. & $*$ & $*$ \\
\hline & $B\left(f t_{\bullet}-I_{.}\right)$ & 3,700 & 3,700 & & $B$ (ft. $-I$. & 74.0 & 74.0 \\
\hline & $\overline{\Delta B} / B$ & .022 & .259 & & $\overrightarrow{\triangle \mathrm{B}} / \mathrm{B}$ & .036 & .358 \\
\hline
\end{tabular}

Anode Current $<0.5 \mu \mathrm{A}$. 
TABIE D-6

Electro Vision: Detection Thresholds (Volts) vs. Ambient/Background Brightness (Light Position $=30^{\circ} ;$ Observer Position $=0^{\circ}$ )

\begin{tabular}{|c|c|c|c|c|c|}
\hline $\begin{array}{l}\text { Ambient } \\
\text { (ft. - c.) }\end{array}$ & Observer & $\begin{array}{l}\text { Detection } \\
\text { Threshold } \\
\text { (Volts) }\end{array}$ & $\begin{array}{l}\text { Working } \\
\text { Preference } \\
\text { (Volts) }\end{array}$ & $\begin{array}{cc} & \text { Detection } \\
\text { Ambient } & \text { Threshold } \\
\text { (ft.-c.) Observer (Volts) }\end{array}$ & $\begin{array}{l}\text { Working } \\
\text { Preference } \\
\text { (Volts) }\end{array}$ \\
\hline \multirow[t]{8}{*}{10,000} & RK & 44.70 & 41.50 & & \\
\hline & WK & 44.10 & 41.75 & & \\
\hline & $\mathrm{BB}$ & 44.20 & 41.96 & & \\
\hline & $\overline{\mathrm{V}}$ & 44.33 & 41.74 & & \\
\hline & $\overline{\Delta B}$ (ft. - I. & 3.10 & 35.0 & & \\
\hline & $\mu \mathrm{A}$ & $*$ & 1.0 & & \\
\hline & $B\left(f t .-L_{.}\right)$ & ) 83.0 & 83.0 & & \\
\hline & $\overline{\Delta \mathrm{B}} / \mathrm{B}$ & .0373 & .4217 & & \\
\hline \multirow[t]{8}{*}{5,000} & RK & 45.00 & 41.84 & & \\
\hline & WK & 44.00 & 41.88 & & \\
\hline & $\mathrm{BB}$ & *类枮 & $* * *$ & & \\
\hline & $\overline{\mathrm{V}}$ & 44.50 & 41.86 & & \\
\hline & $\overline{\Delta B}\left(f t_{0}-I_{0}\right)$ & ) 2.40 & 33.0 & & \\
\hline & $\mu \mathrm{A}$. & $*$ & 1.0 & & \\
\hline & $B$ fft. - L. & 50.0 & 50.0 & & \\
\hline & $\overline{\triangle \mathrm{B}} / \mathrm{B}$ & .048 & .660 & & \\
\hline
\end{tabular}

* Anode Current $<0.5 \mu \mathrm{A}$. CRT Shorted 


\section{TABLE D-7}

Hartman: Detection Thresholds (Volts) vs. Ambient/Background Brightness $\left(\right.$ Light Position $=30^{\circ} ;$ Observer Position $\left.=0^{\circ}\right)$

\begin{tabular}{|c|c|c|c|c|c|c|c|}
\hline \multirow{2}{*}{$\begin{array}{l}\begin{array}{l}\text { Ambient } \\
\left(\mathrm{ft} .-\mathrm{c}_{.}\right)\end{array} \\
10,000\end{array}$} & \multicolumn{2}{|c|}{$\begin{array}{r}\text { Detection } \\
\text { Threshold } \\
\text { Observer (Volts) }\end{array}$} & $\begin{array}{l}\text { Working } \\
\text { Preference } \\
\text { (Volts) }\end{array}$ & Ambien & \multicolumn{2}{|c|}{$\begin{array}{l}\text { Detection } \\
\text { Threshold } \\
\text { er (Volta) }\end{array}$} & $\begin{array}{l}\text { Working } \\
\text { Preferenc } \\
\text { (Volts) }\end{array}$ \\
\hline & RK & 34.90 & 31.86 & 1,000 & RK & 35.60 & 33.34 \\
\hline & WK & 34.40 & 32.66 & & WK & 35.30 & 33.94 \\
\hline & $\mathrm{BB}$ & 34.40 & 32.63 & & $\mathrm{BB}$ & 35.40 & 34.44 \\
\hline & $\bar{V}$ & 34.57 & 32.38 & & $\bar{V}$ & 35.43 & 33.91 \\
\hline & $\overline{\Delta B}\left(f t_{0}-L_{.}\right)$ & 1.20 & 23.0 & & $\overline{\Delta B}$ (ft. - L & .260 & 3.80 \\
\hline & $\mu A$. & $*$ & $*$ & & $\mu \mathrm{A}$. & $*$ & $*$ \\
\hline & B(ft. - L. & ) 21.0 & 21.0 & & B(ft. - I & .) 3.20 & 3.20 \\
\hline & $\overline{\Delta B} / B$ & .057 & 1.095 & & $\overline{\Delta B} / B$ & .082 & 1.188 \\
\hline 5,000 & RI & 35.20 & 33.28 & 100 & RK & 36.30 & 34.56 \\
\hline & WK & 34.90 & 32.83 & & WK & 36.10 & 34.97 \\
\hline & $\mathrm{BB}$ & 35.00 & 33.30 & & $\mathrm{BB}$ & 36.20 & 35.01 \\
\hline & $\overline{\mathrm{V}}$ & 35.03 & 33.14 & & $\overline{\mathrm{V}}$ & 36.20 & 34.85 \\
\hline & $\overline{\Delta B}$ (ft. - L. & ). .540 & 11.0 & & $\overline{\Delta B}(f t ., I$ & .060 & .740 \\
\hline & $\mu \mathrm{A}$. & $*$ & $*$ & & $\mu \mathrm{A}$. & $*$ & $*$ \\
\hline & $B$ (ft. - L. & ) 16.5 & 16.5 & & $B$ (ft. - I & .) .410 & .410 \\
\hline & $\overline{\Delta \mathrm{B}} / \mathrm{B}$ & .033 & .667 & & $\overline{\Delta B} / B$ & .146 & 1.804 \\
\hline
\end{tabular}

* Anode Current $<0.5 \mu \mathrm{A}$. 
TABLE D-8

Fairchild: Detection Thresholds (Volts) vs. Ambient/Background Brightness $\left(\right.$ Light Position $=30^{\circ}$, Observer Position $\left.=0^{\circ}\right)$

\begin{tabular}{|c|c|c|c|c|c|c|c|}
\hline \multirow{2}{*}{$\begin{array}{l}\begin{array}{l}\text { Ambient } \\
\left(\mathrm{ft} .-\mathrm{c}_{.}\right)\end{array} \\
10,000\end{array}$} & \multirow{2}{*}{$\frac{{ }_{\text {Observer }}^{T}}{\mathrm{TK}}$} & \multirow{2}{*}{$\begin{array}{c}\begin{array}{c}\text { Detection } \\
\text { Threshold } \\
\text { (Volts) }\end{array} \\
19.40\end{array}$} & \multirow{2}{*}{$\begin{array}{c}\begin{array}{c}\text { Working } \\
\text { Preference } \\
\text { (Volts) }\end{array} \\
14.72\end{array}$} & $\begin{array}{l}\text { Ambien } \\
\text { (ft. -c.) }\end{array}$ & \multicolumn{2}{|c|}{$\begin{array}{r}\text { Detection } \\
\text { Threshold } \\
\text { Observer(Volts) }\end{array}$} & \multirow{2}{*}{$\begin{array}{c}\begin{array}{c}\text { Working } \\
\text { Preference } \\
\text { (Volts) }\end{array} \\
17.91\end{array}$} \\
\hline & & & & \multirow[t]{8}{*}{1,000} & RK & 22.00 & \\
\hline & WK & 19.00 & 10.60 & & WK & 21.70 & 19.39 \\
\hline & $\mathrm{BB}$ & 19.00 & 14.60 & & $\mathrm{BB}$ & 21.70 & 20.00 \\
\hline & $\overline{\mathrm{V}}$ & 19.13 & 13.31 & & $\overrightarrow{\mathrm{V}}$ & 21.80 & 19.10 \\
\hline & \multicolumn{2}{|c|}{$\overrightarrow{\Delta B}$ (ft. - L.) 9.60} & 43.0 & & \multicolumn{2}{|c|}{$\overline{\Delta B}$ (ft. - L.) .76} & 10.0 \\
\hline & $\mu \mathrm{A}$ & 2.2 & 27.0 & & \multicolumn{2}{|c|}{$\mu \mathrm{A} . \quad *$} & 2.2 \\
\hline & $B$ (ft. - I. & ) 245 & 245 & & \multicolumn{2}{|c|}{$B\left(f t .-I_{.}\right) 28.0$} & 28.0 \\
\hline & $\overline{\Delta \mathrm{B}} / \mathrm{B}$ & .039 & .176 & & $\overline{\Delta \mathrm{B}} / \mathrm{B}$ & .027 & .357 \\
\hline \multirow[t]{8}{*}{5,000} & RK & 20.60 & 14.60 & \multirow[t]{8}{*}{100} & RK & 22.80 & 21.00 \\
\hline & WK & 20.30 & 14.39 & & WK & 22.80 & 21.42 \\
\hline & $\mathrm{BB}$ & 20.10 & 14.70 & & $\mathrm{BB}$ & 22.90 & 21.42 \\
\hline & $\overline{\mathrm{V}}$ & 20.33 & 14.56 & & $\overline{\mathrm{V}}$ & 22.83 & 21.28 \\
\hline & $\bar{\Delta} \vec{B}(f t .-L$. ) & 4.20 & 36.0 & & $\overline{\Delta \mathrm{B}}$ (ft. - L. & .064 & 1.60 \\
\hline & $\mu A$ & $*$ & 18.0 & & $\mu \mathrm{A}$ & $*$ & $*$ \\
\hline & $B$ (ft. - L. & ) 135 & 135 & & $B$ (ft. $-L$. & 2.80 & 2.80 \\
\hline & $\overrightarrow{\triangle \mathrm{B}} / \mathrm{B}$ & .031 & .266 & & $\overline{\Delta \mathrm{B}} / \mathrm{B}$ & .023 & .571 \\
\hline
\end{tabular}


DARIEN, CONNECTICUT 06821

One Parkland Drive

Area Code $203 \quad 655-3971$

In N Y C , WYandotte 3-2464

Execufive Offices

System Scrences Division

Management Research

\& Consulting Division

NEW YORK, NEW YORK 10017

200 Park Avenue

Area Code 212 661-2160

Management Research

\& Consulting Division

WASHINGTON, D C 20007

1050 Thırty-Fırst Street, N W

Area Code 202 333-0100

DUNLAP and ASSOCIATES, INC

System Scrences Division

WESTERN DIVISION

SANTA MONICA, CALIFORNIA 90404

1454 Cloverfield Boulevard

Area Code 213 393-0166

Western Division

MANHATTAN, KANSAS 66503

200 Research Drive

Area Code 913 JEfferson 9-3565

Agri Research DIVISIOn 